\title{
ON THE ELEMENTARY ELECTRICAL CHARGE AND THE AVOGADRO CONSTANT.
}

By R. A. Millikan.

\section{INTRODUCTORY.}

$\mathrm{T}^{\mathrm{H}}$ $\mathrm{HE}$ experiments herewith reported were undertaken with the view of introducing certain improvements into the oil-drop method ${ }^{1}$ of determining $e$ and $N$ and thus obtaining a higher accuracy than had before been possible in the evaluation of these most fundamental constants.

In the original observations by this method such excellent agreement was found between the values of $e$ derived from different measurements (1. c., p. 384) that it was evident that if appreciable errors existed they must be looked for in the constant factors entering into the final formula rather than in inaccuracies in the readings or irregularities in the behavior of the drops. Accordingly a systematic redetermination of all these constants was begun some three years ago. The relative importance of the various factors may be seen from the following review.

As is now well known the oil-drop method rested originally upon the assumption of Stokes's law and gave the charge $e$ on a given drop through the equation

$$
e_{n}=\frac{4}{3} \pi\left(\frac{9 \eta}{2}\right)^{\frac{3}{3}}\left(\frac{\mathrm{I}}{g(\sigma-\rho)}\right)^{\frac{1}{2}} \frac{\left(v_{1}+v_{2}\right) v_{1}^{\frac{1}{2}}}{F}
$$

in which $\eta$ is the coefficient of viscosity of air, $\sigma$ the density of the oil, $\rho$ that of the air, $v_{1}$ the speed of descent of the drop under gravity and $v_{2}$ its speed of ascent under the influence of an electric field of strength $F$.

The essential feature of the method consisted in repeatedly changing the charge on a given drop by the capture of ions from the air and in thus obtaining a series of charges with each drop. These charges showed a very exact multiple relationship under all circumstances-a fact which demonstrated very directly the atomic structure of the electric charge. If Stokes's law were correct the greatest common divisor of this series of charges should have been the absolute value of the elementary electrical charge. But the fact that this greatest common divisor failed to come out a constant when drops of different sizes were used showed that Stokes's

${ }^{1}$ R. A. Millikan, Phys. Rev., 32, pp. 349-397, I9Ir. 
law breaks down when the diameter of a drop begins to approach the order of magnitude of the mean free path of a gas molecule. Consequently the following corrected form of Stokes's law for the speed of a drop falling under gravity was suggested.

$$
v_{1}=\frac{2}{9} \frac{g a^{2}(\sigma-\rho)}{\eta}\left\{\mathrm{I}+A \frac{l}{a}\right\},
$$

in which $a$ is the radius of the drop, $l$ the mean free path of a gas molecule and $A$ an undetermined constant. It is to be particularly emphasized that the term in the brackets was expressly set up merely as a first order correction term in $l / a$ and involved no theoretical assumptions of any sort; further that the constant $A$ was empirically determined through the use only of small values of $l / a$ and that the values of $e$ and $N$ obtained were therefore precisely as trustworthy as were the observations themselves. This fact has been repeatedly overlooked in criticisms of the results of the oil-drop method.

Calling then $e_{1}$ the greatest common divisor of all the various values of $e_{n}$ found in a series of observations on a given drop there resulted from the combination of (I) and (2) the equation

$$
e\left(\mathrm{I}+A \frac{l}{a}\right)^{\frac{3}{2}}=e_{1},
$$

or

${ }^{1}$ Indeed M. Jules Roux (Compt. Rendu, I52, p. I I68, May, |I.9I I) has attempted to correct my values of $e$ and $N$ by reducing some observations like mine which he made on droplets of sulphur, with the aid of a purely theoretical value of $A$ which is actually approximately twice too large. The impossibility of the value of $A$ which he assumes he would himself have discovered had he made observations on spheres of different sizes or at different pressures. Such observations whether made on solid spheres or on liquid spheres always yield a value of $A$ about half of that assumed by Roux. Hence his value of $e$, viz., $e=4.17 \times 10^{-10}$ rests on no sort of experimental foundation whatsoever. It rests rather on two erroneous assumptions, first the assumption of the correctness of the constants in Cunningham's theoretical equation (Proc. Roy. Soc., 83, p. 357; see also footnote 3, p. 380, Phys. Rev., Vol. 32)-constants which I shall presently show are in no case correct within the limits of experimental error even when inelastic impact is assumed, and second, the assumption that molecules make elastic impact against solid surfaces, an assumption which is completely incorrect as I had already proved by showing that the value of the "slip" term is the same for oil and air as for glass and air (Prys. REv.. Vol. 32, p. 382), which Knudsen also had proved experimentally to be erroneous (Knudsen, An. der Phys., 28, p. 75, 1909, and 35, p. 389) and which for theoretical reasons as well is plainly inadmissible, since were it correct Poiseuille's law could not hold for gases under any circumstances.

But even if Roux had assumed the correct value of $A$ he would still have obtained results several per cent. too low, a fact which must be ascribed either to faulty experimental arrangements or to imperfect knowledge of the density of his sulphur spheres; for solid spheres have been very carefully studied in the Ryerson Laboratory and are in fact found to yield results very close to those obtained with oil drops. Solid spheres however are not nearly so well adapted to a precision measurement of $e$ as are oil drops, since their density and sphericity are always matters of some uncertainty. 


$$
e=\frac{e_{1}}{\left(\mathrm{I}+A \frac{l}{a}\right)^{\frac{3}{2}}} .
$$

It was from this equation that $e$ was obtained after $A$ had been found by a graphical method which will be more fully considered presently.

The factors then which enter into the determination of $e$ are: (I) The density factor, $\sigma-\rho$; (2) the electric field strength, $F$; (3) the viscosity of air, $\eta$; (4) the speeds, $v_{1}$ and $v_{2} ;(5)$ the drop radius, $a$; (6) the correction term constant, $A$.

Concerning the first two of these factors little need be said unless a question be raised as to whether the density of such minute oil drops might not be a function of the radius. Such a question is conclusively answered in the negative both by theory ${ }^{1}$ and by the experiments reported in this paper.

Liquid rather than solid spheres were originally chosen because of the far greater certainty with which their density and sphericity could be known. Nevertheless I originally used liquids of widely different viscosities (light oil, glycerine, mercury) and obtained the same results with them all within the limits of error, thus showing experimentally that so far as this work was concerned, the drops all acted like rigid spheres. More complete proof of this conclusion is furnished both by the following observations and by other careful work on solid spheres soon to be reported in detail by $\mathrm{Mr}$. J. Y. Lee.

The material used for the drops in the following experiments was the highest grade of clock-oil, the density of which, at $23^{\circ} \mathrm{C}$., the temperature

1 The pressure $p_{2}$ within an oil drop is given by

$$
p_{2}=k+\frac{\alpha}{2 R}
$$

where $k$ is LaPlace's constant of internal pressure, $\alpha$ the constant of surface tension and $R$ the radius. The difference $\left(p_{2}-p_{1}\right)$ between the pressure within the oil drop and within the oil in bulk is then $\alpha / 2 R$. But the coefficient of compressibility of a liquid is defined by

$$
\beta=\frac{v_{2}-v_{1}}{v_{1}\left(p_{2}-p_{1}\right)} .
$$

Now $\beta$ for oil of this sort never exceeds $70 \times 10^{-6}$ megadynes per sq. $\mathrm{cm}$. (see Landolt and Bornstein's tables), while $\alpha$ is about 35 dyne cm. $R$ for the smallest drop used (Table XX.) is $.00005 \mathrm{~cm}$.; we have then

$$
\frac{v_{2}-v_{1}}{v_{1}}=\beta \frac{\alpha}{2 R}=\frac{70 \times 10^{-12} \times 35}{.0001}=.000024
$$

The density of the smallest drop used is then 2 parts in 100,000 greater than that of the oil in bulk. The small drops could then only be appreciably denser than the larger ones if the oil were inhomogeneous and if the atomizing process selected the heavier constituents for the small drops. Such an assumption is negatived by the experimental results given in $\S 9$. 
at which the experiments were carried out, was found in two determinations made four months apart, to be .9I99 with an error of not more than one part in Io,ooo.

The electric fields were produced by a 5,300-volt storage battery, the P.D. of which dropped on an average 5 or Io volts during an observation of an hour's duration. The potential readings were taken, just before and just after a set of observations on a given drop, by dividing the bank into 6 parts and reading the P.D. of each part with a 90o-volt Kelvin and White electrostatic voltmeter which showed remarkable constancy and could be read easily, in this part of the scale, with an accuracy of about I part in 2,00o. This instrument was calibrated by comparison with a 750-volt Weston Laboratory Standard Voltmeter certified correct to I/Io per cent. and actually found to have this accuracy by comparison with an instrument standardized at the Bureau of Standards in Washington. The readings of P.D. should therefore in no case contain an error of more than I part in I,Ooo. As a matter of fact 5,000 volt readings made with the aid of two different calibration curves of the K. \& W. instrument made two years apart never differed by more than $\mathrm{I}$ or 2 parts in 5,000 .

The value of $F$ involves in addition to P.D. the distance between the plates, which was as before $16 \mathrm{~mm}$. and correct to about .o I $\mathrm{mm}$. (1. c., p. 35I). Nothing more need be said concerning the first two of the above-mentioned factors. The last four however need especial consideration.

\section{The Coefficient of Viscosity of Air.}

This factor certainly introduces as large an element of uncertainty as inheres anywhere in the oil-drop method. Since it appears in equation ( $I$ ) in the $3 / 2$ power an uncertainty of 0.5 per cent. in $\eta$ means an uncertainty of 0.75 per cent. in $e$. It was therefore of the utmost importance that $\eta$ be determined with all possible accuracy. Accordingly two new determinations were begun three years ago in the Ryerson Laboratory, one by Mr. Lachlan Gilchrist and one by Mr. I. M. Rapp. Mr. Gilchrist, whose work has already been published, ${ }^{1}$ used a constant deflection method (with concentric cylinders), which it was estimated (1. c., p. 386) ought to reduce the uncertainty in $\eta$ to I or 2 tenths of a per cent. The results have justified this estimate. Mr. Rapp used a form of the capillary tube method which it was thought was better adapted to an absolute evaluation of $\eta$ than have been the capillary tube arrangements which have been commonly used heretofore. ${ }^{2}$ Since $\mathrm{Mr}$.

${ }^{1}$ Lachlan Gilchrist, Phys. Rev., 2d Ser., Vol. x, p. I24.

${ }^{2}$ This investigation will shortly be published in full (PHys. Rev., I9r3), hence only a bare statement will here be made of the results which are needed for the problem in hand. 
Gilchrist completed his work at the University of Toronto, Canada, and Mr. Rapp made his computations and final reductions at Ursinus College, Pa., neither observer had any knowledge of the results obtained by the other. The two results agree within I part in 600. Mr. Rapp estimates his maximum uncertainty at 0.1 per cent., Mr. Gilchrist at 0.2 per cent. Mr. Rapp's work was done at $26^{\circ} \mathrm{C}$. and gave $\eta_{26}=.00018375$. When this is reduced to $23^{\circ} \mathrm{C}$., the temperature used in the following work, by means of formula (5)-a formula ${ }^{1}$ which certainly can introduce no appreciable error for the range of temperature here used,- -viz.,

there results

$$
\eta_{t}=0.00018240-0.000000493(23-t) ;
$$

$$
\eta_{23}=.00018227 \text {. }
$$

Mr. Gilchrist's work was done at $20.2^{\circ} \mathrm{C}$. and gave $\eta_{20.2}=.00018 \mathrm{I} 2$. When this is reduced to $23^{\circ} \mathrm{C}$. it yields

$$
\eta_{23}=.00018257 \text {. }
$$

When this new work, by totally dissimilar methods, is compared with the best existing determinations by still other methods the agreement is exceedingly striking. Thus in $1905, \mathrm{Hogg}^{2}$ made at Harvard very careful observations on the damping of oscillating cylinders and obtained in three experiments at atmospheric pressure $\eta_{23}=0.0001825, \quad \eta_{15.6}=$ 0.0001790 and $\eta_{18.6}=0.0001795$. These last two reduced to $23^{\circ} \mathrm{C}$., as above, are 0.0001826 and 0.0001817 respectively and the mean value of the three determinations is

$$
\eta_{23}=0.00018227 .
$$

Tomlinson's classical determination, ${ }^{3}$ by far the most reliable of the nineteenth century, yielded when the damping was due primarily to "push" $\eta_{12.65^{\circ} \mathrm{C}}=0.000 \mathrm{I} 7746$; when it was due wholly to "drag" $\eta_{11.79^{\circ} \mathrm{C}}$ $=0.000177 \mathrm{II}$. These values reduced to $15^{\circ} \mathrm{C}$., as above, are respectively 0.00017862 and 0.000I7867. Hence we may take Tomlinson's direct determination as $\eta_{15}=0.00017864$. This reduced to $23^{\circ} \mathrm{C}$. by Tomlinson's own temperature formula (Holman's) yields $\eta_{23}=$ 0.00018242 . By the above formula it yields $\eta_{23}=0.00018256$.

Grindley and Gibson using the tube method on so large a scale ${ }^{4}$ (tube I/8 inch in diameter and I08 feet long) as to largely eliminate the most

${ }^{1}$ See R. A. Millikan, Annalen der Physik, I9I3, for a more extended discussion of this and other viscosity formulæ and measurements.

2 J. L. Hogg, Proc. Amer. Acad., 40, I8, p. 6I I, I905.

3 Tomlinson, Phil. Trans., I77, p. 767, I886.

${ }^{4}$ Grindley and Gibson, Proc. Roy. Soc., 80, p. II4, 1908. 
fruitful sources of error in this method, namely, the smallness and ununiformity of the bore, obtained at room temperature the following results: ${ }^{1} \eta_{25.28^{\circ} \mathrm{C} .}=.00018347, \eta_{23.55^{\circ} \mathrm{C} .}=.0001824 \mathrm{I}, \eta_{12.18^{\circ} \mathrm{C} .}=.00018257$, and $\eta_{15.4^{\circ} \mathrm{C} .}=.0001782$. These numbers, reduced to $23^{\circ} \mathrm{C}$. as above, are respectively $\mathrm{I} 8,245, \mathrm{I} 8,24 \mathrm{I}, \mathrm{I} 8,20 \mathrm{I}$, and $\mathrm{I} 8, \mathrm{I} 95$. The mean is $\mathrm{I} 8,220$. Grindley and Gibson's own formula, $\eta=.0001702\{\mathbf{I}+.00329 t-$ $\left..000007 \mathrm{o} t^{2}\right\}$, yields $\eta_{23}=.00018245$. We may take then Grindley and Gibson's direct determination as the mean of these two values, viz.: $\eta_{23}=.00018232$.

Collecting then the five most careful determinations of the viscosity of air which so far as I am able to discover have ever been made we obtain the following table.

\section{TABLE I.}

Air $\eta_{23}=.00018227$-Rapp. Capillary tube method. 1913.

Air $\eta_{23}=.00018257$-Gilchrist. Constant deflection method. 1913.

Air $\eta_{23}=.00018227$ - Hogg. Damping of oscillating cylinder method. 1905 .

Air $\eta_{23}=.00018258$-Tomlinson. Damping of pendular vibrations method. 1886 .

Air $\eta_{23}{ }^{\prime}=.00018232-$ Grindley and Gibson. Flow through large pipe method. 1908.

Mean $=\overline{.00018240}$

It will be seen, then, that every one of the five different methods which have been used for the absolute determination of $\eta$ leads to a value which differs by less than I part in I,ooo from the above mean value $\eta_{23}=$ .00018240. It is surely legitimate then to conclude that the absolute value of $\eta$ for air is now known with an uncertainty of somerwhat less than I part in $I, O O .^{2}$

${ }^{1}$ These numbers represent the reduction to absolute C.G.S. units of all the observations which Grindley and Gibson made between $50^{\circ} \mathrm{F}$. and $80^{\circ} \mathrm{F}$.

${ }^{2}$ In obtaining the above mean I have chosen what, after careful study, I have considered to be the best determination by each of the five distinct methods. The transpiration method has been much more commonly used than have the others, and in general, the final result is in good agreement with other careful work by this method. Thus Rankine's final value (Proc. Roy. Soc., $A, 83, \cdot$ p. 522 , r9ro) by a new modification of the capillary tube method, while probably not claiming an accuracy of more than .4 per cent., is, at $10.6^{\circ} \mathrm{C} ., .0001767$, a value which reduces to $\eta_{23}=.0001828$. Again Fisher's final formula (Phys. Rev., 28, p. 104, I909) gives $\eta_{23}=.00018218$. Also Holman's much used formula (Phil. Mag., 21, p. 199, I886, and Tomlinson, Phil. Trans., Vol. I77, part 2, p. 767, 1886) yields $\eta_{23}=.00018237$. In fact the only reliable work on $\eta$ which $I$ am able to find which is out of line with the value $\eta_{23}=.00018240$ is that by Breiterbach at Leipzig (Ann. der Phys., 5, p. 166, 190r) and that by Schultze (Ann. der Phys., 5, p. 157, r9or) and several other observers at the University of Halle who used Schultze's apparatus (Markowski, Ann. der Phys., I4, p. 742, 1904, and Tanzler, Verh. der D. Phys. Ges., 8, p. 222, 1906). None of these observers however were aiming at an absolute determination, but rather at the effects of temperature and the mixing of gases upon viscosity and their capillaries were too small (of the order $.007 \mathrm{~cm}$.) to make possible an absolute determination of high accuracy. Their agreement among themselves upon a value which is about I.3 per cent. too high is partly accounted for by the fact that everal of them used the same tube. None of the m made any effort to eliminate the necessarily large error in the measurement of so small a bore (which appears in the result in the fourth power) by taking the mean of $\eta$ from a considerable number of tubes. 
A second question which might be raised in connection with $\eta$ is as to whether the medium offers precisely the same resistance to the motion through it of a heavily charged drop as to that of an uncharged drop. This question has been carefully studied and definitely answered in the affirmative by the following work (cf. $\$ \$ 6$ and ro).

\section{The Speeds $v_{1}$ AND $v_{2}$.}

The accuracy previously attained in the measurement of the times of ascent and descent between fixed cross-hairs was altogether satisfactory, but the method which had to be employed for finding the magnifying power of the optical system, $i$. e., for finding the actual distance of fall of the drop in centimeters, left something to be desired. This optical system was before a short-focus telescope of such depth of focus that it was quite impossible to obtain an accurate measure of the distance between the cross-hairs by simply bringing a standard scale into sharp focus immediately after focusing upon a drop. Accordingly, as stated in the original article, the standard scale was set up at the exact distance from the telescope of the pin-hole through which the drop entered the field. This distance could be measured with great accuracy but the procedure assumed that the drop remained exactly at this distance throughout the whole of any observation, sometimes of several hours duration. But if there were the slightest lack of parallelism between gravity and the lines of the electric field the drop would be obliged to drift slowly, and always in the same direction, away from this position, and a drift of $5 \mathrm{~mm}$. was enough to introduce an error of I per cent. Such a drift could in no way be noticed by the observer if it took place in the line of sight; for the speeds of the drops were changing very slowly anyway because of evaporation, fall in the potential of the battery, etc., and a change in time due to such a drift would be completely masked by other causes of change. This source of uncertainty was well recognized at the time of the earlier observations and steps were taken at the beginning of the present work to eliminate it. It was in fact responsible for an error of nearly two per cent.

A new optical system was built, consisting of an achromatic objective of $28 \mathrm{~mm}$. aperture and $12.5 \mathrm{~cm}$. focal length and an eyepiece of $\mathrm{I} 2 \mathrm{~mm}$. focal length. The whole system was mounted in a support which could be moved bodily back and forth by means of a horizontal screw of $1 / 2 \mathrm{~mm}$. pitch. In an observation the objective was $25 \mathrm{~cm}$. distant from the drop, which was kept continually in sharp focus by advancing or withdrawing the whole telescope system. The depth of focus was so small that a motion of $1 / 2 \mathrm{~mm}$. blurred badly the image of the drop. The eyepiece 
was provided with a scale having 80 horizontal divisions and the distance between the extreme divisions of this scale (the distance of fall in the following experiments) could be regularly duplicated with an accuracy of at least I part in I,ooo, by bringing a standard scale (Société Genevoise) into sharp focus. (The optical path when the scale was viewed was made exactly the same as when the drop was viewed.) The distance of fall, then, one of the most uncertain factors of the preceding determination, was now known with at least this degree of precision.

The accuracy of the time determinations can be judged from the data in Tables IV.-XIX. On account of the great convenience of a direct-reading instrument these time measurements were all made, not with a chronograph, as heretofore, but with a Hipp chronoscope which read to 0.002 second. This instrument was calibrated by comparison with the standard Ryerson Laboratory clock under precisely the same conditions as those under which it was used in the observations themselves and found to have an error between 0 and 0.2 per cent. depending upon the time interval measured. For the sake of enabling others to check all the computations herein contained if desired, as well as for the sake of showing what sort of consistency was attained in the measurement of time intervals there are given in Table II. the calibration readings for the 30 sec. interval and in Table III. the results of similar readings for all the intervals used.

TABLE II.

TABLE III.

\begin{tabular}{c|c|c|c|c}
\hline \multicolumn{2}{c|}{ Chronoscope Readings for 3o Sec. Interval. } & $\begin{array}{c}\text { Clock Interval, } \\
\text { Sec. }\end{array}$ & $\begin{array}{c}\text { Chronoscope } \\
\text { Interval. }\end{array}$ & $\begin{array}{c}\text { Corr'n Applied, } \\
\text { Per Cent. }\end{array}$ \\
\cline { 2 - 4 } 29.962 & 29.990 & 6 & 6.0146 & -0.26 \\
29.988 & 29.958 & 10 & 10.0018 & 0.00 \\
29.986 & 29.920 & 16 & 16.0080 & 0.00 \\
29.930 & 29.972 & 20 & 19.9835 & +0.07 \\
29.964 & 29.976 & 30 & 29.9695 & +0.10 \\
30.002 & 30.006 & 40 & 39.9436 & +0.14 \\
29.940 & 29.979 & 60 & 59.9072 & +0.16 \\
29.998 & 30.018 & 114 & 113.795 & +0.20 \\
29.930 & 29.926 & 120 & 119.782 & +0.20 \\
\hline 29.967 & 29.972 & & & \\
\hline \multicolumn{2}{c}{ Corr'n =+.1 per cent. } & & \\
\hline
\end{tabular}

The change in the per cent. correction with the time interval employed is due to the difference in the reaction times of the magnet and spring contact at make (beginning) and at break (end). All errors of this sort are obviously completely eliminated by making the calibration observations under precisely the same conditions as the observations on the drop. In Tables IV. to XIX. the recorded times are the uncorrected chronograph 
readings. The corrections are obtained by interpolation in the last column of Table III.

Under the head of possible uncertainties in the velocity determinations are to be mentioned also the effects of a distortion of the drop by the electric field. Such a distortion would increase the surface of the drop, and hence the speed imparted to it per dyne of electric force would not be the same as the speed imparted per dyne of gravitational force when the field was off and the drop had the spherical form. The following observations were made in such a way as to bring to light such an effect if it were of sufficient magnitude to exert any influence whatever upon the accuracy of the determination of $e$ by this method (cf. $\$ \S 6$ and ro).

Similarly objection has been made to the oil-drop method on the ground that, on account of internal convection, fluid drops would not move through air with the same speed as solid drops of like diameter and mass. Such objection is theoretically unjustifiable in the case of oil drops of the sizes here considered. ${ }^{1}$ Nevertheless the experimental demonstration of its invalidity is perhaps worth while and is therefore furnished below.

\section{The Radius " $a . "$}

The radius of the drop enters only into the correction term (see equation 4) and so long as this is small need not be determined with a high degree of precision. It is most easily obtained by the following procedure which differs slightly from that originally employed (1. c., p. 379).

It will be seen that the equation (1. c., p. 353)

$$
\frac{v_{1}}{v_{2}}=\frac{m g}{F e-m g}
$$

contains no assumption whatever save that a given body moves through a given medium with a speed which is proportional to the force acting upon it. Substitution in this equation of $m=\frac{4}{3} \pi a^{3}(\sigma-\rho)$ and the solution of the resulting equation for $a$ gives

$$
a=\sqrt[3]{\frac{3 F e}{4 \pi g(\sigma-\rho)} \frac{v_{1}}{\left(v_{1}+v_{2}\right)}} .
$$

The substitution in this equation of an approximately correct value of $e$ yields $a$ with an error but one third as great as that contained in the assumed value of $e$. The radius of the drop can then be determined from (7) with a very high degree of precision as $e$ becomes more and more accurately known. In the following work the value of $e$ substituted in (7) to obtain $a$ was $4.78 \times 10^{-10}$ but the final value of $e$ obtained would

\footnotetext{
1 Hadamard, Compt. Rendus, Igrr.
} 
not have been appreciably different if the value substituted in (7) to obtain $a$ had been 5 per cent. or 6 per cent. in error. The determination of $a$ therefore introduces no perceptible error into the evaluation of $e$.

\section{The Correction-Term Constant $A$.}

This constant was before graphically determined (1. c., p. 379) by plotting the values of $e_{1}^{\frac{2}{3}}$ as ordinates and those of $l / a$ as abscissæ and observing that if we let $x=l / a, y=e_{1}^{\frac{2}{3}}$ and $y_{0}=e^{\frac{2}{3}}$ equation (3) may be written in the form

$$
y_{0}(\mathrm{I}+A x)=y
$$

or

$$
A=\frac{\frac{d y}{d x}}{y_{0}}=\frac{\text { slope }}{y \text { intercept }} .
$$

Now even if the slope were correctly determined by the former observations all of the above-mentioned sources of error would enter into the value of the intercept and hence would modify the value of $A$.

As a matter of fact however the accuracy with which the slope itself was determined could be much improved, for with the preceding arrangement it was necessary to make all the observations at atmospheric pressure and the only way of varying $l / a$ was by varying $a, i$. e., by using drops of different radii. But when $a$ was very small the drops moved exceedingly slowly under gravity and the minutest of residual convection currents produced relatively large errors in the observed speeds, $i$. e., in $e_{1}$. If for example the time of fall over a distance of $2 \mathrm{~mm}$. is 20 minutes it obviously requires an extraordinary degree of stagnancy to prevent a drift in that time of say $.2 \mathrm{~mm}$. due to convection. But this would introduce an error of Io per cent. into $e_{1}$. Furthermore with these slow drops Brownian movements introduce errors which can only be eliminated by taking a very large number of readings ${ }^{1}$ and this is not in general feasible with such drops. It is quite impossible then by working at a single pressure to obtain from the graph mentioned above a line long enough (1. c., p. 379) to make the determination of its slope a matter of great precision. Accordingly in the new observations the variation of $l / a$ was effected chiefly through the variation of $l, i . e$. , of the pressure $p$, rather than of $a$. This made possible not only the accurate evaluation of $e$, but also the solution of the interesting question as to the law of fall of a given drop through air at reduced pressures.

${ }^{1}$ Fletcher, Phys. Rev., 33, p. 92, I9Ir. 


\section{Method of Testing the Assumptions Involved in the Oil-Drop} METHOD.

In order to make clear the method of treatment of the following observations a brief consideration of the assumptions underlying the oil-drop method must here be made. These assumptions may be stated thus:

I. The drag which the medium exerts upon a given drop is unaffected by its charge.

2. Under the conditions of observation the oil drops move through the medium essentially as would solid spheres. This assumption may be split into two parts and stated thus: Neither (2a) distortions due to the electric field nor $(2 b)$ internal convection within the drop modify appreciably the law of motion of an oil drop. ${ }^{1}$

3. The density of oil droplets is independent of their radius down to $a=.00005 \mathrm{~cm}$.

Of these assumptions $(2 a)$ is the one which needs the most careful experimental test. ${ }^{2}$ It will be seen that it is contained in the fundamental equation of the method (see (7)) which may be written in the form

$$
e_{n}=\frac{m g}{F v_{1}}\left(v_{1}+v_{2}\right)
$$

Or still more conveniently in the form

$$
e_{n}=\frac{m g t_{g}}{F}\left(\frac{\mathrm{I}}{t_{g}}+\frac{\mathrm{I}}{t_{F}}\right)
$$

in which $t_{g}$ and $t_{F}$ are the respective time intervals required by the drop to fall under gravity and to rise under the field $F$ the distance between the cross-hairs.

In order to see how the assumption under consideration can be tested let us write the corresponding equation after the same drop has caught $n^{\prime}$ additional units, namely,

$$
e_{n+n^{\prime}}=\frac{m g t_{g}}{F}\left(\frac{\mathrm{I}}{t_{g}}+\frac{\mathrm{I}}{t_{F^{\prime}}}\right) .
$$

The subtraction of (I I) from (I2) gives

$$
e_{n^{\prime}}=\frac{m g t_{g}}{F}\left(\frac{\mathbf{I}}{t_{F}^{\prime}}-\frac{\mathbf{I}}{t_{F}}\right) \text {. }
$$

${ }^{1}$ M. Brillouin has in addition suggested (see p. I49, La Théorie du Rayonnement et les Quanta) that the drops may be distorted by the molecular bombardment, but Einstein's reply (1.c., p. I50) to this suggestion is altogether unanswerable, and, in addition, such a distortion, if it existed, would make the value of $e$ given by the oil-drop method too small instead of too large.

2 Professor Lunn has however subjected it to a theoretical study and has in this way demonstrated its validity (PHys. ReV., XXXV., p. 227, I9I2). 
Now equations (II) and (I2) show, since $m g t_{g} / F$ remains constant, that as the drop changes charge the successive values of its charge are proportional to the successive values assumed by the quantity $\left(\mathrm{I} / t_{g}+\mathrm{I} / t_{F}\right)$ and the elementary charge itself is obviously this same constant factor $m g t_{g} / F$ multiplied by the greatest common divisor of all these successive values. It is to be observed too that since $\mathrm{I} / t_{g}$ is in these experiments generally large compared to $I / t_{F}$ the value of this greatest common divisor, which will be denoted by $\left(\mathrm{I} / t_{g}+\mathrm{I} / t_{F}\right)_{0}$, is determined primarily by the time of fall under gravity, and is but little affected by the time in the field. On the other hand equation (I3) shows that the greatest common divisor of the various values of $\left(\mathrm{I} / t_{F}{ }^{\prime}-\mathrm{I} / t_{F}\right)$, which will be designated by $\left(\mathrm{I} / t_{F}{ }^{\prime}-\mathrm{I} / t_{F}\right)_{0}$, when multiplied by the same constant factor $m g t_{g} / F$, is also the elementary electrical charge. In other words $\left(\mathrm{I} / t_{g}+\mathrm{I} / t_{F}\right)_{0}$ and $\left(\mathrm{I} / t_{F^{\prime}}-\mathrm{I} / t_{F}\right)_{0}$ are one and the same quantity, but while the first represents essentially a speed measurement when the field is off, the second represents a speed measurement in a powerful electric field. If then the assumption under consideration is correct we have two independent ways of obtaining the quantity which when multiplied by the constant factor $m g t_{g} / F$ is the elementary electrical charge, but if on the other hand the distortion of the drop by the field modifies the law of motion of the oil drop through the medium then $\left(\mathrm{I} / t_{g}+\mathrm{I} / t_{F}\right)_{0}$ and $\left(\mathrm{I} / t_{F}{ }^{\prime}-\mathrm{I} / t_{F}\right)_{0}$ will not be the same. Now a very careful experimental study of the relations of $\left(\mathrm{I} / t_{g}+\mathrm{I} / t_{F}\right)_{0}$ and $\left(\mathrm{I} / t_{F^{\prime}}-\mathrm{I} / t_{F}\right)_{0}$ shows so perfect agreement that no effect of distortion in changing measurably the value of e can be admitted. ${ }^{1}$ (See Tables IV. to XIX.)

Turning next to assumption (I), this can be tested in three ways, all of which have been tried with negative results. First a drop containing from one up to six or seven elementary charges can be completely discharged and its time of fall under gravity when uncharged compared with its time when charged. Second, the multiple relationships shown in the successive charges carried by a given drop may be very carefully examined. They cannot hold exactly if when the drop is heavily charged it suffers a larger drag from the medium than when it is lightly charged. Third, when drops having widely different charges and different masses are

\footnotetext{
${ }^{1}$ It may be pointed out in passing that the above discussion brings to light a method of obtaining $e$ which is independent of a viscosity measurement; for $\left(\mathrm{I} / t_{F^{\prime}}-\mathrm{I} / t_{F}\right)_{0}$ can be obtained for a body which is heavy enough to be weighed upon a micro-balance. Such a body would fall so rapidly that $\mathrm{r} / t_{g}$ could not be measured, but it could be computed from the measurement of $\mathrm{I} / t_{F^{\prime}}$ and $\mathrm{I} / t_{F}$ and the equation $\left(\mathrm{I} / t_{g}+\mathrm{I} / t_{F}^{*}\right)_{0}=\left(\mathrm{I} / t_{F^{\prime}}-\mathrm{I} / t_{F}\right)_{0}$. Either (I2) or (13) could then be solved for $e$ after $m$ had been determined by direct weighing. A consideration of the sources of error in this method shows however that it cannot be made as accurate as the present method which involves the coefficient of viscosity of air.
} 
brought to the same value of $l / a$ by varying the pressure, the value of $e_{1}$ (which is proportional to $\left.\left(v_{1}+v_{2}\right)_{0}\right)$, should come out smaller for the heavily than for the lightly charged drops. The following observations show that this is not the case.

The last criterion is also a test for $(2 b)$ for if internal convection modifies the speed of fall of a drop as Perrin wishes to assume that it may, ${ }^{1}$ it must play a smaller and smaller rôle as the drop diminishes in size, hence varying $l / a$ by diminishing $a$ cannot be equivalent to varying $l / a$ by increasing $l$. In other words the value of $e_{1}$ obtained from work on a large drop at a low pressure should be different from that obtained from work on a small drop at so high a pressure that $l / a$ has the same value as for the large drop.

Finally if the density of a small drop is greater than that of a large one (see assumption 3 ) then, for a given value of $l / a$, the small drop will show a larger value of $e_{1}$ than the large one inasmuch as the computation of $e_{1}$ is based on a constant value of $\sigma$. The fact, then, that for a given value of $l / a$ the value of $e_{1}$ actually comes out independent of the radius or charge of the drops shows conclusively either that no one of these possible sources of error exists, or else that they neutralize one another so that for the purposes of this experiment they do not exist. That they do not exist at all is shown by the independent theoretical and experimental tests mentioned above. This removes I think every criticism which has been suggested of the oil-drop method of determining $e$ and $N$.

\section{Summary of Improvements in Method.}

In order to obtain the consistency shown in the following observations it was found necessary to take much more elaborate precautions to suppress convection currents in the air of the observing chamber than had at first been thought needful.

To recapitulate, then, the improvements which have been introduced into the oil-drop method, consist in (I) a redetermination of $\eta ;(2)$ an improved optical system; (3) an arrangement for observing speeds at all pressures; (4) the more perfect elimination of convection; (5) the experimental proof of the correctness of all the assumptions underlying the method, viz., $(a)$ that a charge does not alter the drag of the medium on the charged body; $(b)$ that the oil drops act essentially like solid spheres; (c) that the density of the oil drops is the same as the density of the oil in bulk.

${ }^{1}$ La Théorie du Rayonnement et les Quanta, p. 239-Rapports et Discussions de la Réunion tenueà Bruxelles, Novembre, rgrr. Edited by Langevin and de Broglie. GauthierVillars. 


\section{The Experimental Arrangements.}

The experimental arrangements are shown in Fig. I. The brass vessel $D$ was built for work at all pressures up to ${ }_{5} 5$ atmospheres but since the present observations have to do only with pressures from $76 \mathrm{~cm}$. down these were measured with a very carefully made mercury manometer $m$ which at atmospheric pressure gave precisely the same reading as a

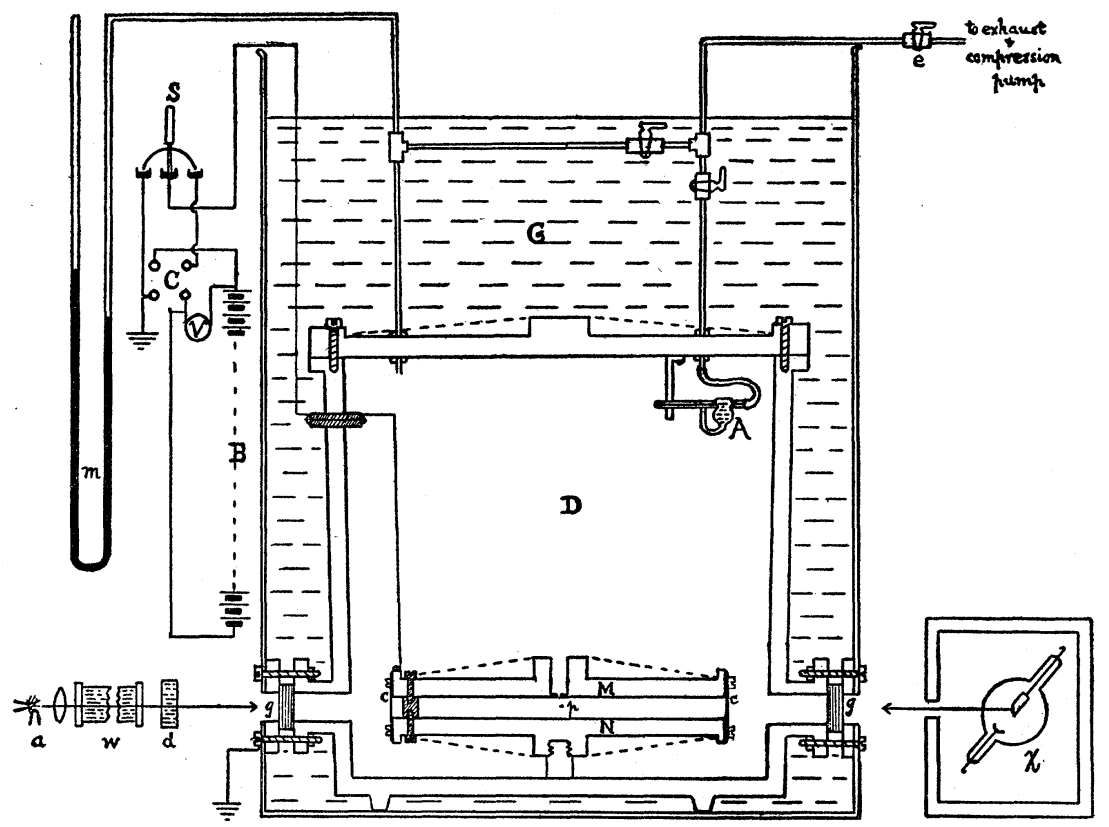

Fig. 1.

standard barometer. Complete stagnancy of the air between the condenser plates $M$ and $N$ was attained first by absorbing all of the heat rays from the arc $A$ by means of a water cell $w, 80 \mathrm{~cm}$. long, and a cupric chloride cell ${ }^{1} d$, and second by immersing the whole vessel $D$ in a constant temperature bath $G$ of gas-engine oil (40 liters) which permitted, in general, fluctuations of not more than $.02^{\circ} \mathrm{C}$. during an observation. This constant temperature bath was found essential if such consistency of measurement as is shown below was to be obtained. A long search for causes of slight irregularity revealed nothing so important as this and after the bath was installed all of the irregularities vanished. The atomizer $A$ was blown by means of a puff of carefully dried and dust-free air introduced through the $\operatorname{cock} e$. The air about the drop $p$ was ionized

\footnotetext{
${ }^{1}$ See Coblentz, Bulletin of the Bureau of Standards, Washington, D. C., Vol. 7, p. 66o,
} I9I. 
when desired by means of Röntgen rays from $X$ which readily passed through the glass window $g$. To the three windows $g$ (two only are shown) in the brass vessel $D$ correspond, of course, three windows in the ebonite strip $c$ which encircles the condenser plates $M$ and $N$. Through the third of these windows, set at an angle of about $18^{\circ}$ from the line $X p a$ and in the same horizontal plane, the oil drop is observed.

\section{The Observations.}

The record of a typical set of readings on a given drop is shown in Table IV. The first column, headed $t_{g}$, gives the successive readings on the time of descent under gravity. The fourth column, headed $t_{F_{c}}$ gives the successive times of ascent under the influence of the field $F$ as measured on the Hipp chronoscope. These two columns contain all the data which is used in the computations. But in order to have a test of the stagnancy of the air a number of readings were also made with a stop-watch on the times of ascent through the first half and through the whole distance of ascent. These readings are found in the second and third columns, the times for the first half under the head $1 / 2 t_{F_{s}}$, the times for the whole distance under the head $t_{F_{s}}$. It will be seen from these readings that there is no indication whatever of convection, since the readings for the one half distance have uniformly one half of the value of the readings for the whole distance, within the limits of error of a stop-watch measurement. This sort of a test was made on the majority of the drops, but since no further use is made of these stop-watch readings they will not be given in succeeding tables.

The fifth column, headed $\mathbf{I} / t_{F}$, contains the reciprocals of the values in the fourth column after the correction found from Tables II. and III. has been applied. The sixth column contains the successive differences in the values of $\mathbf{I} / t_{F}$ resulting from the capture of ions. The seventh column, headed $n^{\prime}$, contains the number of elementary units caught at each change, a number determined simply by observing by what number the quantity just before it in column 6 must be divided to obtain the constancy shown in the eighth column, which contains the successive determinations of $\left(\mathrm{I} / t_{F}{ }^{\prime}-\mathrm{I} / t_{F}\right)_{0}$ (see $\left.\S 6\right)$. Similarly the ninth column, headed $n$, gives the total number of units of charge on the drop, a number determined precisely as in the case of the numbers in the seventh column by observing by what numbers the successive values of $\left(\mathrm{I} / t_{g}+\mathrm{I} / t_{F}\right)$ must be divided to obtain the constancy shown in the tenth column, which contains the successive values of $\left(\mathrm{I} / t_{g}+\mathrm{I} / t_{F}\right)_{0}$. Since $n^{\prime}$ is always a small number and in some of the changes almost always has the value $I$ or 2 its determination for any change is obviously never a matter of the slightest 
uncertainty. On the other hand, $n$ is often a large number, but with the aid of the known values of $n^{\prime}$ it can always be found with absolute certainty so long as it does not exceed say Ioo or I5O. It will be seen from the means at the bottom of the eighth and the tenth columns that in the case of this drop the two ways discussed in $\$ 6$ of obtaining the number which when multiplied by $m g t_{g} / F$ is the elementary electrical charge yield absolutely identical results.

TABLE IV.

Drop No. 6.

\begin{tabular}{|c|c|c|c|c|c|c|c|c|c|}
\hline Sec. & $\begin{array}{l}\frac{1}{2} t F_{8} \\
\text { Sec. }\end{array}$ & $\begin{array}{c}t_{F_{s}} \\
\text { Sec. }\end{array}$ & $\begin{array}{l}{ }^{t_{F}} F_{c} \\
\text { Sec. }\end{array}$ & $\frac{I}{t_{F}}$ & $\left(\frac{\mathrm{I}}{t_{F^{\prime}}}-\frac{\mathrm{I}}{t_{F}}\right)$ & $n^{\prime}$ & $\frac{x}{n}\left(\frac{x}{t_{F}^{\prime}}-\frac{x}{t_{F}}\right)$ & $n$ & $\frac{\mathrm{I}}{n}\left(\frac{\mathrm{I}}{t_{g}}+\frac{\mathrm{x}}{t_{F}}\right)$ \\
\hline 11.848 & 39.9 & 80.2 & 80.708 & .01236 & & & & 18 & .005366 \\
\hline 11.890 & 11.2 & 22.4 & 22.3667 & & .03234 & 6 & .005390 & & \\
\hline 11.908 & & & 22.390 & .04470 & & & & 24 & .005371 \\
\hline 11.904 & 11.2 & 22.4 & 22.368 & & .03751 & 7 & .005358 & & \\
\hline 11.882 & 70.6 & 140.4 & 140.565 & .007192 & & 1 & & 17 & .005375 \\
\hline 11.906 & 39.9 & 79.6 & 79.600 & .01254 & & 1 & & 18 & .005374 \\
\hline 11.838 & & & $34.748]$ & & .01616 & 3 & .005387 & & \\
\hline 11.816 & & & 34.762 & .02870 & & & & 21 & .005376 \\
\hline 11.776 & & & 34.846 & & & & & & \\
\hline 11.840 & & & $29.286^{-1}$ & 03414 & & & & 22 & .005379 \\
\hline 11.904 & 14.6 & 29.3 & 29.236 & .03414 & .026872 & 5 & .005375 & 22 & \\
\hline 11.870 & 69.3 & 137.4 & 137.308 & $.007268\}$ & & & & 17 & .005380 \\
\hline 11.952 & 17.6 & 34.9 & 34.638 & $.02884\}$ & & 4 & & 21 & .005382 \\
\hline 11.860 & & & & & .01623 & 3 & .005410 & & \\
\hline 11.846 & & & 22.104 & & & & & & .005386 \\
\hline 11.912 & & & 22.268 & & .04307 & 8 & .005384 & 24 & \\
\hline 11.910 & , & & 500.1 & .002000 & & & & 16 & .005387 \\
\hline 11.918 & & & $19.704^{-}$ & 05070 & .04879 & 9 & .005421 & 25 & .005399 \\
\hline 11.870 & & & $19.668]$ & עינד & 03874 & 7 & 005401 & & \\
\hline 11.888 & & & 77.6307 & & $.038 / 4$ & & .000401 & 18 & .005390 \\
\hline 11.894 & 38.9 & 77.6 & 77.806 & .0128 & & 2 & & & \\
\hline 11.878 & 21.0 & 42.6 & 42.302 & .02364 & $.010 / 9$ & & .005395 & 20 & .005392 \\
\hline 11.880 & & & & & Means & & .005386 & & .005384 \\
\hline
\end{tabular}

Duration of exp. $=45 \mathrm{~min}$.,

Plate distance $=16 \mathrm{~mm}$.,

Fall distance $\quad=10.21 \mathrm{~mm}$.

Initial volts $\quad=5,088.8$.

Final volts $\quad=5,081.2$.

Temperature $\quad=22.82^{\circ} \mathrm{C}$.,

Pressure $\quad=75.62 \mathrm{~cm}$.

Oil density $\quad=.9199$,

Air viscosity ${ }^{1}=1,824 \times 10^{-7}$

Radius $(a) \quad=.000276 \mathrm{~cm}$.

$l / a \quad=.034$,

Speed of fall $=.08584 \mathrm{~cm} . / \mathrm{sec}$.

$$
e_{1}=4.991 \times 10^{-10} \text {. }
$$

1 In the above and in all the following tables the computations were made on the basis of the assumption $\eta_{23}=\mathrm{I}, 825 \times \mathrm{IO}^{-7}$ instead of $\eta_{23}=\mathrm{I}, 824 \times 10^{-7}$ (see $\S 2$ ). The reduction to the latter value has been made only in the final value of $e$ (see $\S 10$ ). 
TABle V.

Drop No. 16 .

\begin{tabular}{|c|c|c|c|c|c|c|c|}
\hline$t_{g}$ & $t_{F}$ & $\frac{I}{t_{F}}$ & $n^{\prime}$ & $\frac{1}{n^{\prime}}\left(\frac{1}{t_{F}^{\prime}}-\frac{1}{t_{F}}\right)$ & $n$ & $\frac{\mathbf{x}}{n}\left(\frac{\mathbf{I}}{t_{g}}+\frac{\mathbf{x}}{t_{F}}\right)$ & \\
\hline $\begin{array}{l}18.638 \\
18.686 \\
18.689 \\
18.730 \\
18.686 \\
18.726 \\
18.772 \\
18.740 \\
18.724 \\
18.720 \\
18.816 \\
18.816 \\
18.716 \\
18.804 \\
18.746 \\
18.746 \\
18.790 \\
\mathbf{1 8 . 7 3 8}\end{array}$ & $\left.\begin{array}{c}17.756 \\
17.778\end{array}\right]$ & $\left.\begin{array}{l}.05628 \\
.02174\end{array}\right\}$ & $\begin{array}{l}5 \\
4 \\
2\end{array}$ & $\begin{array}{l}.006908 \\
.006795 \\
.006860 \\
.006825 \\
.006866\end{array}$ & \begin{tabular}{r|}
13 \\
9 \\
11 \\
12 \\
11 \\
9 \\
11
\end{tabular} & $\begin{array}{l}.006855 \\
.006868 \\
.006867 \\
.006856 \\
.006876 \\
.006876 \\
.006879\end{array}$ & $\begin{aligned} V_{i} & =\mathbf{5 1 0 6} \\
V_{\mathcal{J}} & =\mathbf{5 1 0 0} \\
t & =23.7^{\circ} \mathrm{C} . \\
p & =74.68 \\
v_{1} & =.05449 \\
a & =.0002188 \\
l / a & =.04390 \\
\mathbf{e}_{1} & =\mathbf{5 . 0 6 5}\end{aligned}$ \\
\hline
\end{tabular}

TABle VI.

Drop No. 14 .

\begin{tabular}{|c|c|c|c|c|c|c|c|}
\hline$t_{g}$ & $t_{F}$ & $\frac{I}{t_{F}}$ & $n^{\prime}$ & 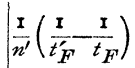 & $n$ & $\frac{x}{n}\left(\frac{x}{t_{g}}+\frac{x}{t_{F}}\right)$ & \\
\hline $\begin{array}{l}18.606 \\
18.732 \\
18.784 \\
18.700 \\
18.730 \\
18.652 \\
18.656 \\
18.730 \\
18.760 \\
18.708 \\
18.658 \\
18.668 \\
18.826 \\
18.710 \\
18.802 \\
18.778 \\
18.790 \\
18.846 \\
18.804 \\
18.662 \\
18.704\end{array}$ & $\begin{array}{c}46.172 \\
17.896 \\
17.818 \\
46.328 \\
46.258 \\
46.266 \\
67.473 \\
67.148 \\
67.148 \\
17.896 \\
15.868 \\
15.854 \\
730.0 \\
23.376 \\
23.504 \\
65.416 \\
118.970 \\
622.8\end{array}$ & $\left.\begin{array}{l}\{ \\
.01484 \\
.05588\end{array}\right\}$ & $\begin{array}{l}1 \\
1\end{array}$ & $\begin{array}{c}.006874 \\
.006886 \\
.006803 \\
.006840 \\
.006853 \\
.006882 \\
.006850 \\
.006871 \\
.006784\end{array}$ & $\begin{array}{r}10 \\
16\end{array}$ & $\begin{array}{l}.006823 \\
.006831 \\
.006850 \\
.006845 \\
.006861 \\
.006865 \\
.006864 \\
.006874\end{array}$ & $\begin{aligned} V_{i} & =5077 \\
V_{f} & =5073 \\
t & =23.09^{\circ} \mathrm{C} . \\
p & =75.28 \\
v_{1} & =.05451 \\
a & =.0002185 \\
l / a & =.04348 \\
\mathrm{e}_{1} & =\mathbf{5 . 0 6 4}\end{aligned}$ \\
\hline 18.730 & & & & .006850 & & .006844 & \\
\hline
\end{tabular}


In order to show the sort of consistency attained in this work the complete records are given in Tables V., VI., VII., VIII. and IX. of five drops of practically the same size, taken at very nearly the same pressures. These are the only drops of this size which were observed with the present arrangement so that they represent the regular run of observations rather than a selected group. The symbols in the last column $V_{i}, V_{f}, t, p, v_{1}$, and $a$ stand for initial volts, final volts, temperature, pressure, velocity under gravity, and radius, respectively. It will be seen from the second columns (see Table V.) that in general in spite of the precautions taken against evaporation (1. c., p. 388) the drops do evaporate very slowly, since with a given charge the speed in the field very slowly increases. It is for this reason that the numbers in the next to the last column tend to increase very slightly. This slow change introduces no error into $e_{1}$, provided corresponding values of $t_{g}, t_{F}$ and $V$ (volts) are combined to obtain $e_{1}$. The mean values taken throughout the same time-interval

TABLE VII.

Drop No. 18.

\begin{tabular}{|c|c|c|c|c|c|c|}
\hline$t_{g}$ & $t_{F}$ & $n^{\prime}$ & $\frac{I}{n^{\prime}}\left(\frac{I}{t_{F^{\prime}}}-\frac{I}{t_{F}}\right)$ & $n$ & $\frac{\mathbf{x}}{n}\left(\frac{\mathbf{x}}{t_{g}}+\frac{\mathbf{x}}{t_{F}}\right)$ & \\
\hline $\begin{array}{l}18.626 \\
18.716 \\
18.602 \\
18.634 \\
18.694 \\
18.678 \\
18.598 \\
18.612 \\
18.622 \\
18.795 \\
18.732 \\
18.780 \\
18.736 \\
18.754 \\
18.712 \\
18.760 \\
18.716 \\
18.740\end{array}$ & $\left.\begin{array}{r}21.206 \\
21.110 \\
72.590 \\
36.454 \\
48.870 \\
142.838 \\
72.428 \\
36.722 \\
36.652 \\
36.602 \\
140.891 \\
48.302 \\
48.266 \\
20.942\end{array}\right\}$ & $\begin{array}{l}2 \\
1 \\
2\end{array}$ & $\begin{array}{l}.006696 \\
.006820 \\
.006735 \\
.006792 \\
.006732\end{array}$ & $\begin{array}{r}10 \\
12 \\
11 \\
9 \\
10 \\
\\
12\end{array}$ & $\begin{array}{l}.006716 \\
.006726 \\
.006742 \\
.006725 \\
.006722 \\
.006729 \\
.006729 \\
.006732 \\
.006745 \\
.006747\end{array}$ & $\begin{aligned} V_{i} & =5030 \\
V_{f} & =5018 \\
t & =23.0^{\circ} \mathrm{C} . \\
p & =76.06 \\
v_{1} & =.05463 \\
a & =.0002191 \\
l / a & =.04290 \\
\mathbf{e}_{1} & =\mathbf{5 . 0 4 3}\end{aligned}$ \\
\hline 18.695 & & & .006753 & & .006731 & \\
\hline
\end{tabular}

constitute such corresponding values. On account of this slow change, however, the readings from which the differences $\left(\mathbf{I} / t_{F}{ }^{\prime}-\mathbf{I} / t_{F}\right)$ are taken should be separated by as small a time interval as possible. It is for this reason that in Table V., for example, to obtain the difference $\left(\mathrm{I} / t_{F}{ }^{\prime}\right.$ $\left.-\mathrm{I} / t_{F}\right)$ corresponding to the change from $t_{F}=45 \mathrm{sec}$. to $t_{F}=694 \mathrm{sec}$. 
TABLE VIII.

Drop No. 15 .

\begin{tabular}{|c|c|c|c|c|}
\hline$t_{g}$ & $t_{F}$ & $\frac{\mathrm{x}}{n^{\prime}}\left(\frac{\mathrm{I}}{t_{F^{\prime}}}-\frac{\mathrm{I}}{t F^{\prime}}\right)$ & $\frac{\mathrm{I}}{n}\left(\frac{\mathrm{r}}{t_{g}}+\frac{\mathrm{I}}{t_{F^{\prime}}}\right)$ & \\
\hline $\begin{array}{l}18.908 \\
18.948 \\
18.958 \\
18.950 \\
18.904 \\
18.988 \\
18.896 \\
19.094 \\
18.936 \\
18.980 \\
19.030 \\
18.872 \\
18.808 \\
18.910 \\
18.946 \\
18.936 \\
18.950 \\
19.030 \\
19.116 \\
19.018 \\
\end{array}$ & $\left.\begin{array}{c}14.348 \\
14.352 \\
45.070 \\
34.338 \\
34.432 \\
34.334\end{array}\right]$ & $\begin{array}{l}.006807 \\
.006858\end{array}$ & $\begin{array}{l}.006801 \\
.006813 \\
.006816 \\
.00620 \\
.006831\end{array}$ & $\begin{aligned} V_{i} & =5085 \\
V_{f} & =5071 \\
t & =23.83^{\circ} \mathrm{C} . \\
p & =75.24 \\
v_{1} & =.05274 \\
a & =.0002182 \\
l / a & =.04368 \\
\mathrm{e}_{1} & =\mathbf{5 . 0 4 0}\end{aligned}$ \\
\hline 18.959 & & .006817 & .006823 & \\
\hline
\end{tabular}

TABLE IX.

Drop No. 17 .

\begin{tabular}{|c|c|c|c|c|c|c|}
\hline$t_{g}$ & $t_{F}$ & $n^{\prime}$ & $\frac{\mathbf{I}}{n^{\prime}}\left(\frac{\mathrm{I}}{t_{F^{\prime}}}-\frac{\mathbf{I}}{t_{F}}\right)$ & $n$ & $\frac{1}{n}\left(\frac{x}{t_{g}}+\frac{1}{t_{F}}\right)$ & \\
\hline $\begin{array}{l}18.402 \\
18.556 \\
18.350 \\
18.470 \\
18.412 \\
18.318 \\
18.388 \\
18.376 \\
18.406 \\
18.392 \\
18.492 \\
\end{array}$ & $\left.\begin{array}{r}14.966 \\
14.870 \\
37.376 \\
37.594 \\
37.368 \\
50.228 \\
76.154 \\
155.6\end{array}\right\}$ & $\begin{array}{l}1 \\
1 \\
1\end{array}$ & $\begin{array}{l}.006780 \\
.006780 \\
.006682\end{array}$ & $\begin{array}{c}11 \\
10 \\
9\end{array}$ & $\begin{array}{l}.006752 \\
.006748 \\
.006749 \\
.006742 \\
.006749\end{array}$ & $\begin{aligned} V_{i} & =5065 \\
V_{t} & =5055 \\
t & =23.06^{\circ} \mathrm{C} . \\
p & =73.47 \\
v_{1} & =.05545 \\
a & =.0002209 \\
e / a & =.04411 \\
\mathrm{e}_{1} & =5.054 \times 10^{-10}\end{aligned}$ \\
\hline 18.415 & & & .006742 & & .006748 & \\
\hline
\end{tabular}

the last two of the $45 \mathrm{sec}$. readings are averaged instead of the whole four. It is worthy of note, too, in this connection that if a change in the time in the field takes place first from $45 \mathrm{sec}$. to 694 , sec. and then im- 
TABLE X.

Drop No. 42.

\begin{tabular}{|c|c|c|c|c|c|c|}
\hline$t_{g}$ & $t_{F}$ & $n^{\prime}$ & $\frac{\mathbf{I}}{n^{\prime}}\left(\frac{\mathrm{I}}{t_{F^{\prime}}}-\frac{\mathrm{I}}{t_{F^{\prime}}}\right)$ & $n$ & $\frac{\mathbf{x}}{n}\left(\frac{\mathbf{x}}{t_{g}}+\frac{\mathbf{x}}{t_{F}}\right)$ & \\
\hline $\begin{array}{l}18.360 \\
18.362 \\
18.328 \\
18.444 \\
18.442 \\
18.330 \\
18.330 \\
18.428 \\
18.174 \\
18.388 \\
18.392 \\
18.240 \\
18.314 \\
18.324 \\
18.312 \\
18.390 \\
\end{array}$ & $\begin{array}{r}45.378 \\
45.208 \\
15.574 \\
17.468 \\
66.000 \\
66.020 \\
122.600 \\
45.414 \\
45.282 \\
45.110 \\
45.282 \\
121.600 \\
121.200\end{array}$ & $\begin{array}{l}1 \\
2\end{array}$ & $\begin{array}{l}.007027 \\
.007011 \\
\\
.006993 \\
.006951\end{array}$ & $\begin{array}{r}11 \\
17 \\
16 \\
10 \\
9\end{array}$ & $\begin{array}{l}.006960 \\
.006983 \\
.006983 \\
.006965 \\
.006962 . \\
.006960\end{array}$ & $\begin{aligned} V_{i} & =4240 \\
V_{f} & =4236 \\
t & =22.94^{\circ} \mathrm{C} \\
p & =15.72 \mathrm{~cm} . \\
v_{1} & =.05564 \frac{\mathrm{cm} .}{\mathrm{sec} .} \\
a & =.0002060 \mathrm{~cm} . \\
l / a & =.2210 \\
\mathrm{e}_{1} & =6.244 \times 10^{-10}\end{aligned}$ \\
\hline 18.347 & & & .006978 & & .006969 & \\
\hline
\end{tabular}

TAble XI.

Drop No. 46 .

\begin{tabular}{|c|c|c|c|c|c|c|}
\hline$t_{g}$ & ${ }^{t_{F}}$ & $n^{\prime}$ & $\frac{\mathbf{I}}{n^{\prime}}\left(\frac{\mathbf{x}}{t_{F^{\prime}}}-\frac{\mathbf{x}}{t_{F}}\right)$ & $n$ & $\frac{x}{n}\left(\frac{x}{t_{g}}+\frac{x}{t_{F}}\right)$ & \\
\hline $\begin{array}{l}25.856 \\
25.946 \\
25.890 \\
25.876 \\
25.818 \\
25.934 \\
25.956 \\
25.876 \\
26.064 \\
26.018 \\
25.902 \\
25.860 \\
25.930 \\
25.994 \\
25.814 \\
26.012 \\
25.904 \\
25.802 \\
25.918 \\
25.816 \\
\end{array}$ & $\left.\begin{array}{c}10.334 \\
10.342 \\
38.604 \\
53.450 \\
24.906 \\
30.248 \\
30.016 \\
18.282 \\
16.216 \\
24.860 \\
21.062 \\
30.126 \\
20.884 \\
21.130 \\
21.174 \\
85.922 \\
226.600 \\
86.368 \\
86.406\end{array}\right\}$ & $\begin{array}{r}10 \\
1 \\
3\end{array}$ & $\begin{array}{c}.007086 \\
.007195 \\
.007152 \\
.\end{array}$ & $\begin{array}{l}10 \\
13 \\
14 \\
11 \\
12 \\
10\end{array}$ & $\begin{array}{c}.007121 \\
.007159 \\
.007154 \\
.007152 \\
.007172 \\
.007174 \\
.007159 \\
.007161 \\
.007168 \\
.007171 \\
\end{array}$ & $\begin{aligned} V_{i} & =3406 \\
V_{f} & =3396 \\
t & =22.81^{\circ} \mathrm{C} . \\
p & =14.68 \mathrm{~cm} . \\
v_{1} & =.03937 \mathrm{~cm} . \\
a & =.0001690 \frac{\mathrm{cm} .}{\mathrm{sec} .} \\
l / a & =.2886 \\
\mathbf{e}_{1} & =6.719 \times 10^{-10}\end{aligned}$ \\
\hline 25.909 & & & .007160 & & .007161 & \\
\hline
\end{tabular}


mediately back again to the 45 second value the mean of the two values of $\left(\mathrm{I} / t_{F}{ }^{\prime}-\mathrm{I} / t_{F}\right)$ thus obtained is independent of any error arising from the evaporation of the drop. For this reason the mean value of the quantity $\mathrm{I} / n^{\prime}\left(\mathbf{I} / t_{F}{ }^{\prime}-\mathbf{I} / t_{F}\right)$. is in general much more trustworthy than might be inferred from the variation in the individual numbers from which this mean is obtained.

TABLE XII.

Drop No. 53 .

\begin{tabular}{|c|c|c|c|c|c|c|}
\hline$t_{g}$ & $t_{F}$ & $n^{\prime}$ & $\frac{\mathbf{I}}{n^{\prime}}\left(\frac{\mathrm{I}}{t_{F^{\prime}}}-\frac{\mathrm{I}}{t_{F}}\right)$ & $n$ & $\frac{\mathrm{I}}{n}\left(\frac{\mathrm{I}}{t_{g}}+\frac{\mathrm{I}}{t_{F}}\right)$ & \\
\hline $\begin{array}{l}33.432 \\
33.346 \\
33.172 \\
33.310 \\
33.380 \\
33.306 \\
33.346 \\
33.328 \\
33.684 \\
33.484\end{array}$ & $\left.\begin{array}{r}28.494 \\
28.624 \\
20.806 \\
20.832 \\
35.032 \\
28.548 \\
111.244 \\
400.000 \\
111.706\end{array}\right\}$ & $\begin{array}{l}3 \\
1 \\
4 \\
1 \\
1\end{array}$ & $\begin{array}{l}.006501 \\
.006503 \\
.006490 \\
.006505 \\
.006471 \\
.006436\end{array}$ & $\begin{array}{r}10 \\
12 \\
9 \\
10 \\
6 \\
5 \\
6\end{array}$ & $\begin{array}{l}.006491 \\
.006493 \\
.006491 \\
.006491 \\
.006482 \\
.006485 \\
.006475\end{array}$ & $\begin{aligned} V_{i} & =2463 \\
V_{f} & =2440.2 \\
t & =23.16^{\circ} \mathrm{C} . \\
p & =12.61 \\
v_{1} & =.03055 \\
a & =.0001439 \\
l / a & =.3945 \\
e_{1} & =7.450 \times 10^{-10}\end{aligned}$ \\
\hline 33.379 & & & .006484 & & .006487 & \\
\hline
\end{tabular}

TABLe XIII.

Drop No. 48.

\begin{tabular}{|c|c|c|c|c|c|c|c|}
\hline$t_{g}$ & ${ }^{t}$ & $\frac{1}{t_{F}}$ & $n^{\prime}$ & $\frac{x}{n^{\prime}}\left(\frac{x}{t_{F}^{\prime}}-\frac{x}{t_{F}}\right)$ & $n$ & $\frac{\mathbf{x}}{n}\left(\frac{\mathbf{x}}{t_{g}}+\frac{\mathbf{x}}{t_{F}}\right)$ & \\
\hline 32.366 & 20.330 & .04919 & \multirow{5}{*}{5} & & 13 & .006157 & \multirow{9}{*}{$\begin{aligned} V_{i} & =2561 . \\
V_{f} & =2557 . \\
t & =22.81^{\circ} \mathrm{C} . \\
p & =15.35 \mathrm{~cm} . \\
v_{1} & =.03150 \\
a & =.0001501 \mathrm{~cm} . \\
l / a & =.3104 \\
\mathbf{e}_{1} & =6.866 \times 10^{-10}\end{aligned}$} \\
\hline 32.398 & $23.140_{7}$ & & & & & 006165 & \\
\hline 32.217 & $23.230\rfloor$ & $.04313\}$ & & & & . 000105. & \\
\hline 32.342 & 80.7867 & $01231)$ & & .006164 & & 006166 & \\
\hline 32.358 & $81.416^{\rfloor}$ & .01231) & & \multirow{2}{*}{.006137} & & . & \\
\hline 32.438 & 18.1137 & $05517\}$ & 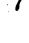 & & 14 & 006144 & \\
\hline 32.412 & $18.144^{\lrcorner}$ & & & \multirow{2}{*}{.006142 } & & & \\
\hline 32.236 & 54.490 & ك & 0 & & 8 & .006147 & \\
\hline 32.424 & 81.486 & .01224 & 1 & .006080 & 7 & .006156 & \\
\hline 32.356 & & & & .006131 & & .006156 & \\
\hline
\end{tabular}

Nevertheless in practically all of the following work in view of the large number of observations in the $t_{g}$ column, the mean at the bottom of the column $\mathrm{I} / n\left(\mathrm{I} / t_{\theta}+\mathrm{I} / t_{F}\right)$ is considered more trustworthy than the mean at the bottom of the column $\mathrm{I} / n^{\prime}\left(\mathbf{I} / t_{F}{ }^{\prime}-\mathbf{I} / t_{F}\right)$ and it has been in fact exclusively used in the computation of $e_{1}$. Only in the case of 2 or 3 of the fastest drops (Tables XVI. and XVII.) are the uncertainties in 
TABLE XIV.

Drop No. 47 .

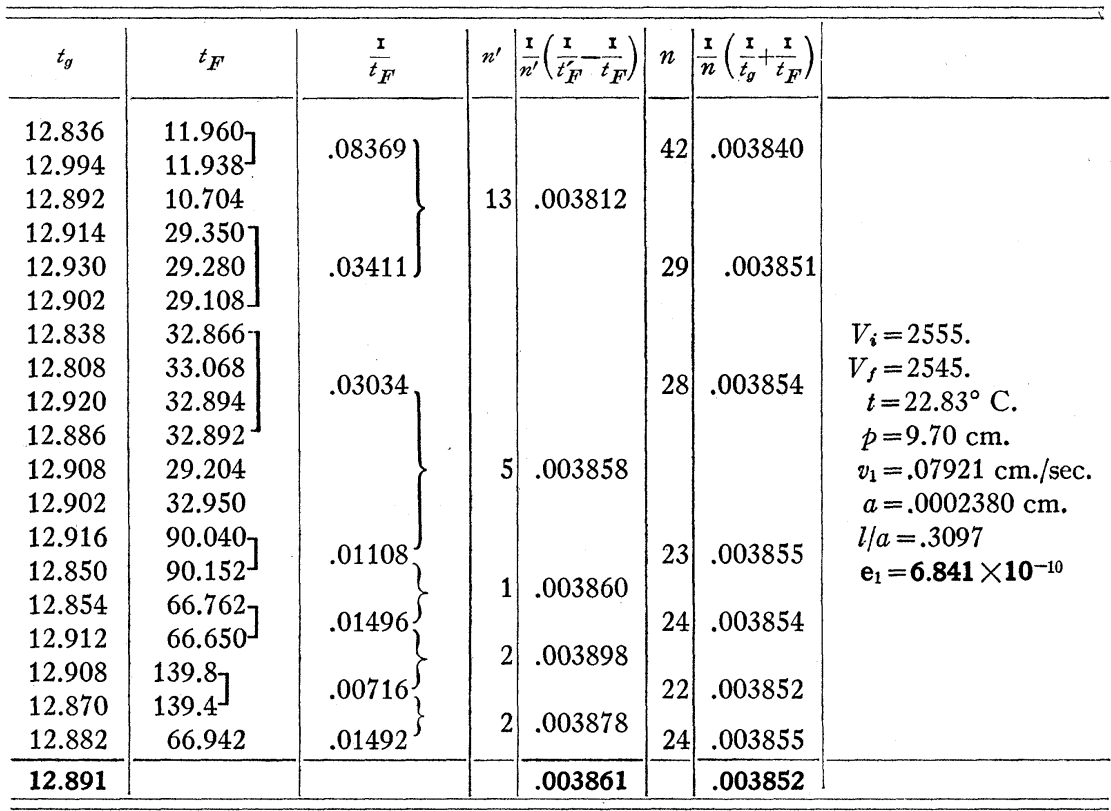

TABLE XV.

Drop No. 41.

\begin{tabular}{|c|c|c|c|c|c|c|c|}
\hline$t_{g}$ & $t_{F}$ & $\frac{I}{t_{F}}$ & $n^{\prime}$ & $\frac{\mathrm{I}}{n^{\prime}}\left(\frac{\mathrm{x}}{t_{F}^{\prime}}-\frac{\mathrm{I}}{t_{F}}\right)$ & $n$ & $\frac{\mathrm{I}}{n}\left(\frac{\mathrm{I}}{t_{g}}+\frac{\mathrm{I}}{t_{F}}\right)$ & \\
\hline 24.016 & 42.1887 & & ; & & & & \\
\hline 24.142 & 42.078 & .02369 & & & 8 & .009336 & \\
\hline 24.130 & 42.098 & & 1 & .009380 & & & \\
\hline 24.070 & 69.900 & .01431 & & & 6 & .009328 & $V_{i}=5065$ \\
\hline 24.000 & 203.200 & .004921 & 1 & .009389 & 5 & .009316 & $V_{f}=5059$ \\
\hline 24.030 & 23.844 & $.04194\}$ & 4 & & 9 & .009286 & $t=23.05^{\circ} \mathrm{C}$ \\
\hline 24.046 & 30.606 & & & & 8 & .009289 & $p=19.01 \mathrm{~cm}$ \\
\hline 24.028 & 42.800 & & & & & & $v_{1}=.04253$ \\
\hline 23.968 & 42.944 & $.02326\}$ & 1 & & 7 & .009276 & $a=.0001816$ \\
\hline 24.018 & 71.4007 & .01400\{ & 1 & & 6 & .009277 & $l / a=.1394$ \\
\hline 23.770 & & & 2 & .009295 & & & $e_{1}=6.097 \times 10^{-10}$ \\
\hline 23.882 & $30.652^{\rfloor}$ & $.03259^{\circ}$ & & & & .009282 & \\
\hline 24.008 & & & & .009314 & & .009301 & \\
\hline
\end{tabular}

$\left(\mathrm{I} / t_{g}+\mathrm{I} / t_{F}\right)_{0}$ greater perhaps than those in $\left(\mathrm{I} / t_{F}{ }^{\prime}-\mathrm{I} / t_{F}\right)_{0}$ and in these cases the two were so near together that there was no object in using the latter instead of the former. It should be stated that all time intervals 
longer than 150 sec. were measured with the stop-watch rather than with the chronoscope and are not subjected to the corrections in Tables II. and III. In general, too, only differences in $t_{F}{ }^{\prime}-t_{F}$ amounting to as much as 20 seconds are used for the determination of $\left(\mathrm{I} / t_{F}{ }^{\prime}-\mathrm{I} / t_{F}\right)$ since obviously the observational error is large when $t_{F}{ }^{\prime}-t_{F}$ is small.

TABLE XVI.

Drop No. 1.

\begin{tabular}{|c|c|c|c|c|c|c|}
\hline$t_{g}$ & ${ }^{t}{ }_{F}$ & $n^{\prime}$ & $\frac{\mathbf{I}}{n^{\prime}}\left(\frac{\mathbf{I}}{t_{F^{\prime}}}-\frac{\mathbf{x}}{t_{F}}\right)$ & $n$ & $\frac{\mathrm{I}}{n}\left(\frac{\mathrm{I}}{t_{g}}+\frac{\mathrm{I}}{t_{F}}\right)$ & \\
\hline 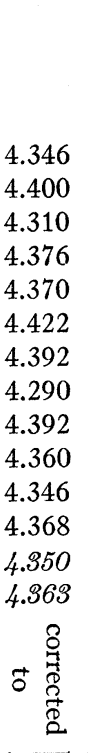 & $\left.\begin{array}{l}\left.\begin{array}{l}17.514 \\
17.500 \\
46.724 \\
46.494 \\
18.722 \\
18.616 \\
56.280 \\
56.276 \\
21.362 \\
21.476\end{array}\right\} \\
\\
58.936 \\
58.194 \\
58.456 \\
58.904 \\
20.412 \\
20.404 \\
20.322\end{array}\right]$ & 11 & $\begin{array}{l}.003244 \\
.003216 \\
.003256 \\
.003217\end{array}$ & $\begin{array}{l}89 \\
78 \\
88 \\
77 \\
86\end{array}$ & $\begin{array}{l}.003219 \\
.003216 \\
.003211 \\
.003218\end{array}$ & $\begin{aligned} V_{i} & =5174 \\
V_{f} & =5162 \\
t & =23.00^{\circ} \mathrm{C} . \\
p & =75.80 \mathrm{~cm} . \\
v_{1} & =.23565 \frac{\mathrm{cm} .}{\mathrm{sec} .} \\
a & =.0005856 \\
l / a & =.01615 \\
\mathrm{e}_{1} & =4.877 \times 10^{-10}\end{aligned}$ \\
\hline $4.328^{1}$ & ' & & .003226 & & .0032245 & \\
\hline
\end{tabular}

A study of Tables IV. to IX. shows, first, a striking agreement between the values of $\left(\mathbf{I} / t_{F}{ }^{\prime}-\mathbf{I} / t_{F}\right)_{0}$ and $\left(\mathbf{I} / t_{g}+\mathbf{I} / t_{F}\right)_{0}$ the largest divergence being found in Table V. where it amounts to 0.3 per cent., and second, a satisfactory agreement between the values of $e_{1}$ obtained from the different

1 These corrected times in Tables XVI. and XVII. are obtained by a slight extrapolation upon a calibration curve plotted from Table III. These two drops are the largest used and fall too rapidly for the most accurate work, but were introduced so as to test as thoroughly as possible the assumptions that even the largest of these drops fall like rigid spheres and that heavily charged drops experience no more drag from the medium than do uncharged ones. The drop of Table XVII. is evaporating more rapidly than any other used (see column $t_{F}$ ), probably because of the low pressure $(4.46 \mathrm{~cm}$.), hence the fourth column numbers, are here obtained only from immediately adjacent observations in the second column. Each of these fourth column numbers shows the influence of the evaporation, but it is interesting to see how it is eliminated from the mean. 
drops of approximately the same size, the largest divergence from the mean value being here too 0.3 per cent.

TABLE XVII.

Drop No. 56.

\begin{tabular}{|c|c|c|c|c|c|c|}
\hline$t_{g}$ & $t_{F}$ & $n^{\prime}$ & $\frac{x}{n^{\prime}}\left(\frac{x}{t_{F^{\prime}}}-\frac{x}{t_{F}}\right)$ & $n$ & $\frac{x}{n}\left(\frac{x}{t_{g}}+\frac{x}{t_{F}}\right)$ & \\
\hline $\begin{array}{r}5.092 \\
5.010 \\
5.082 \\
5.044 \\
- \\
\\
5.044 \\
5.030 \\
\\
5.066 \\
5.120 \\
5.046 \\
5.128 \\
4.912 \\
5.036 \\
5.080 \\
5.122 \\
5.058 \\
\text { cor'd to }\end{array}$ & $\begin{array}{l}\left.\begin{array}{l}19.480 \\
19.356 \\
19.374 \\
19.202 \\
29.214 \\
29.022 \\
28.686 \\
38.688 \\
38.620 \\
75.136 \\
73.752 \\
72.758 \\
33.034 \\
32.788 \\
39.956 \\
46.790 \\
80.820 \\
80.152 \\
55.206 \\
34.398\end{array}\right\} \\
\}\end{array}$ & $\begin{array}{l}3 \\
6\end{array}$ & $\begin{array}{l}.001796 \\
.001877 \\
.001823\end{array}$ & $\begin{array}{r}122 \\
117 \\
126 \\
123 \\
121 \\
116 \\
119 \\
125\end{array}$ & $\begin{array}{l}.001839 \\
.001811 \\
.001814 \\
.001814 \\
.001814 \\
.001816 \\
.001810 \\
.001818\end{array}$ & $\begin{array}{c}V_{i}=1701 \\
V_{f}=1699 \\
t=23.21^{\circ} \mathrm{C} . \\
p=4.46 \mathrm{~cm} . \\
v_{1}=.20256 \\
a=.0003653 \mathrm{~cm} . \\
l / a=.4396 \\
\mathrm{e}_{1}=\mathbf{7 . 7 7 7} \times 10^{-10}\end{array}$ \\
\hline $5.039^{1}$ & 1 & & .001824 & & .001821 & \\
\hline
\end{tabular}

TABLE XVIII.

Drop No. 22.

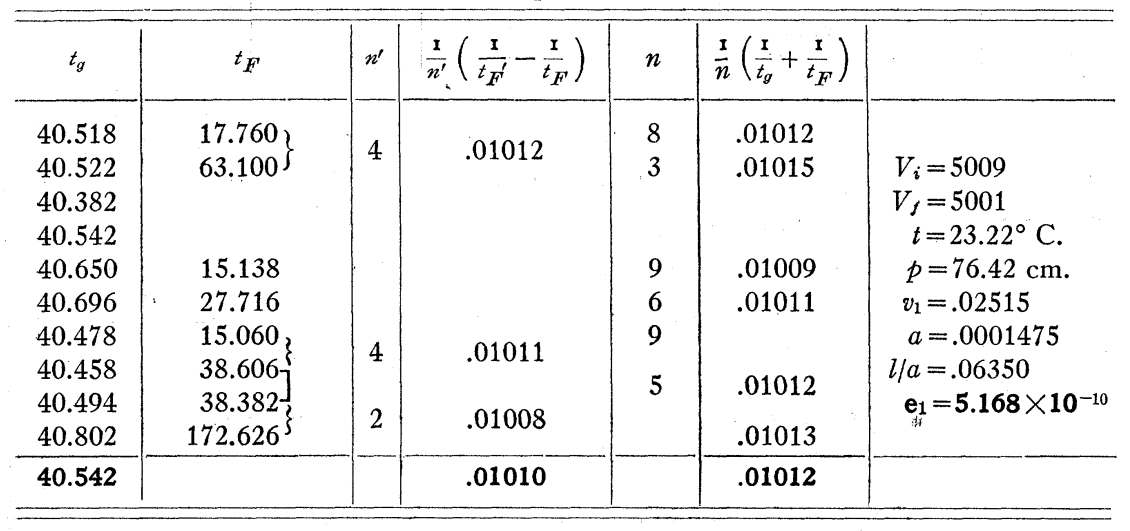

A few typical records of observations made at different pressures (see " $p$," last column) and on drops of different sizes (see " $a$," last column) are presented in Tables X to XIX. 
TABLE XIX.

Drop No. 52.

\begin{tabular}{|c|c|c|c|c|c|c|}
\hline$t_{g}$ & $t_{F}$ & $n^{\prime}$ & $\frac{\mathrm{I}}{n^{\prime}}\left(\frac{\mathrm{I}}{t_{F^{\prime}}}-\frac{\mathrm{I}}{t_{F}}\right)$ & $n$ & $\frac{1}{n}\left(\frac{1}{t_{g}}+\frac{2}{t_{F}}\right)$ & \\
\hline 50.364 & & & & & & $V_{i}=3362$ \\
\hline 50.442 & 44.446 & 1 & & 4 & .010566 & $V_{f}=3340$ \\
\hline 50.416 & $30.254\}$ & 1 & .010515 & & & $t=22.98$ \\
\hline 50.770 & $30.326^{\mathrm{J}}$ & & & 5 & .010556 & $p=16.95$ \\
\hline 50.178 & 22.904 & & & 6 & .010575 & $v_{1}=.020216$ \\
\hline 50.456 & 30.396 & 2 & 7 & 5 & .010532 & $a=.0001183$ \\
\hline 50.460 & $83.716\}$ & 2 & .01047 & 3 & .010573 & $l / a=.3568$ \\
\hline 50.118 & $796.000^{\xi}$ & 1 & .010664 & 2 & .010528 & $\mathrm{e}_{1}=7.210 \times 10^{-10}$ \\
\hline 50.400 & & & .01055 & & .010555 & \\
\hline
\end{tabular}

Table XX. contains a complete summary of the results obtained on all of the $5^{8}$ different drops upon which complete series of observations like the above were made during a period of 60 consecutive days. It will be seen from this table that these observations represent a 30 -fold variation in $l / a$ (from .o16, drop No. I, to .444 , drop No. 58 ), a I 7 -fold variation in $p$ (from $4.46 \mathrm{~cm}$., drop No. 56 , to $76.27 \mathrm{~cm}$., drop No. Io), a I2-fold variation in $a$ (from $4.69 \times \mathrm{IO}^{-5} \mathrm{~cm}$., drop No. 28 , to $58.56 \times \mathrm{IO}^{-5} \mathrm{~cm}$., drop No. I) and a variation in the number of free electrons carried by the drop from I on drop No. 28 to 136 on drop No. 56. The time of fall of drop No. 28 was also tested when it was completely discharged, as have been the times of many other drops which carried most of the time but one electron.

Much larger variations both in $a$ and $p$, and therefore in $l / a$, might have been used, and have in fact been used, for finding the law of fall of a drop through rarefied air, but for the end here sought, namely, the most accurate possible determination of $e$, it was found desirable to keep the $t_{g}$ interval for the most part between the limits Io sec. and 40 sec., in order to avoid chronograph errors on the one hand and Brownian movement irregularities on the other. That neither of these sources of error is appreciable in these observations may be seen from a study of Tables IV.-XIX., which are thoroughly representative of the work on all the drops.

\section{io. Results AND Discussion.}

It will be seen at once from equation (4) that the value of $e$ is simply the value of $e_{1}$ for which $l / a=0$, so that if successive values of $e_{1}^{\frac{3}{3}}$ are plotted as abscissæ and of $l / a$ as ordinates the intercept of the resulting curve on the $e_{1}^{\frac{3}{3}}$ axis is $e^{\frac{3}{3}}$. Furthermore if $A$ is a constant then the curve in question is a straight line and $A$ is the slope of this line divided by the 


\begin{tabular}{|c|c|}
\hline I 34 & R. A. MILLIKAN \\
\hline \multirow[b]{2}{*}{ 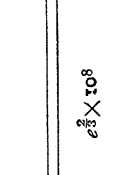 } & $0 z I^{\circ} 19=$ uвә $\mathbb{N}$ \\
\hline & 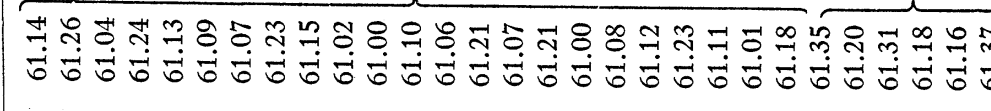 \\
\hline$\underset{\substack { \infty \\
\begin{subarray}{c}{x \\
\infty{ \infty \\
\begin{subarray} { c } { x \\
\infty } }\end{subarray}}{\infty}$ & 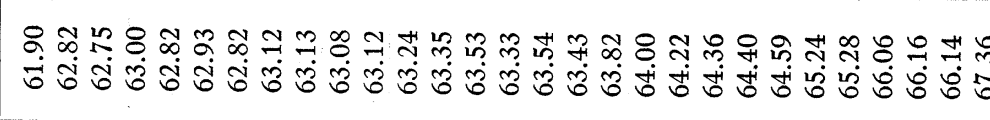 \\
\hline 晜 & 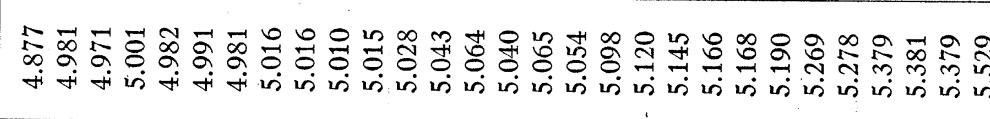 \\
\hline$\approx$ & 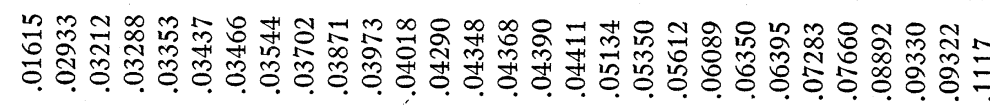 \\
\hline$\frac{\pi}{2}$ & 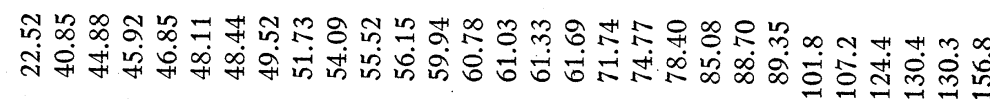 \\
\hline 皇家 & 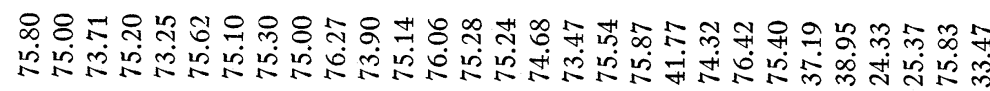 \\
\hline 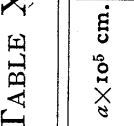 & 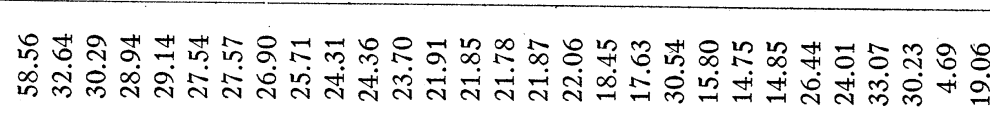 \\
\hline * & 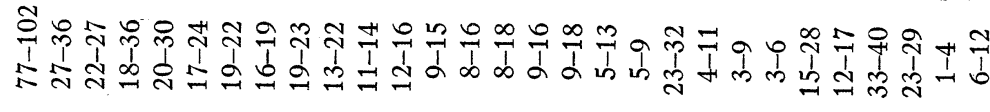 \\
\hline 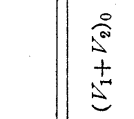 & 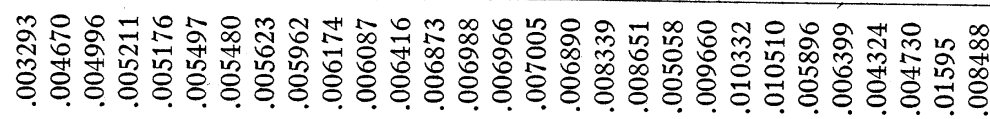 \\
\hline 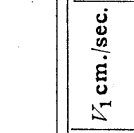 & 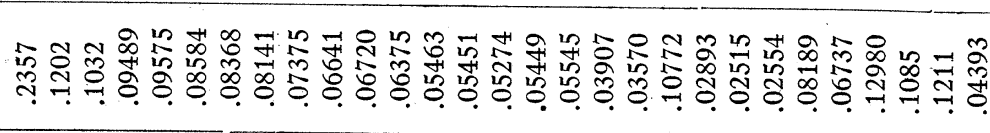 \\
\hline $\begin{array}{l}\dot{\widehat{S}} \\
\stackrel{0}{0} \\
\infty \\
\infty\end{array}$ & 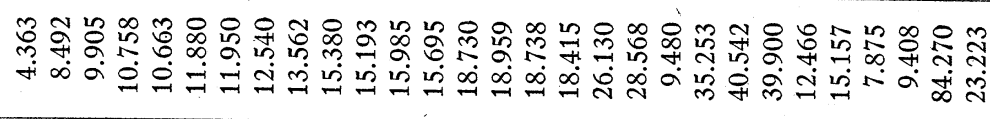 \\
\hline is: & 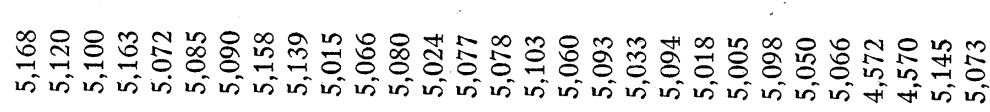 \\
\hline \begin{tabular}{l}
$\dot{0}$ \\
0 \\
$\dot{g}$ \\
\multirow{H}{*}{}
\end{tabular} & 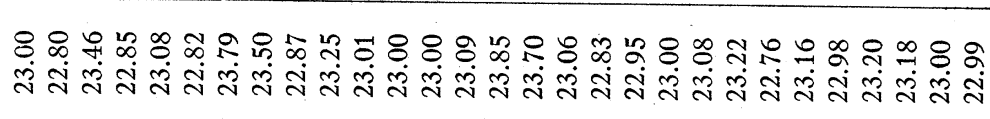 \\
\hline$\dot{z}$ & $n-\infty a 0-\pi m+n$ \\
\hline
\end{tabular}


VoL. II.] ELECTRICAL CHARGE AND AVOGADRO CONSTANT. I 35
No. 2. .

\begin{tabular}{|c|c|}
\hline 赵 & 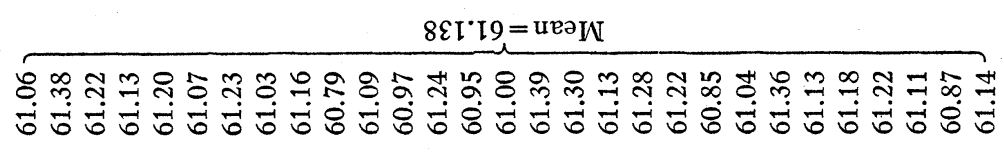 \\
\hline 离 & 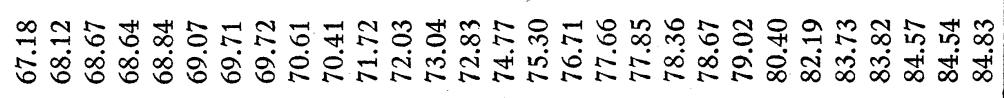 \\
\hline 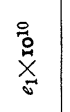 & 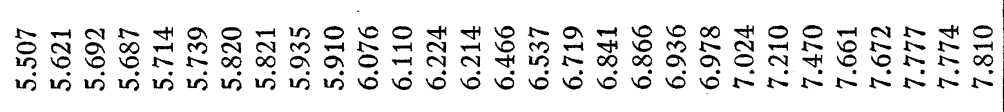 \\
\hline$\stackrel{\otimes}{\sim}$ & 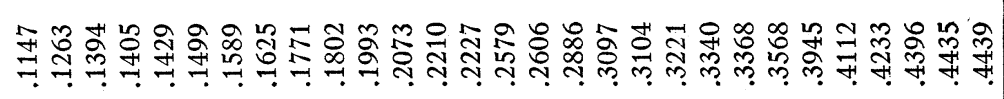 \\
\hline$\frac{\pi}{4}$ & 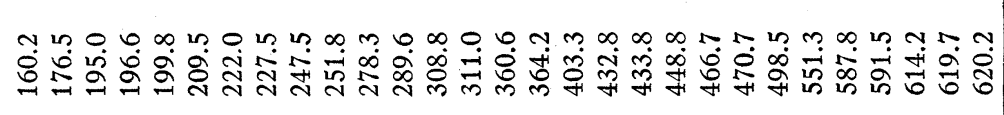 \\
\hline 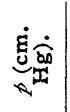 & 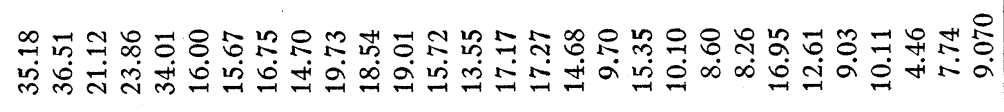 \\
\hline 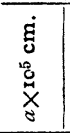 & 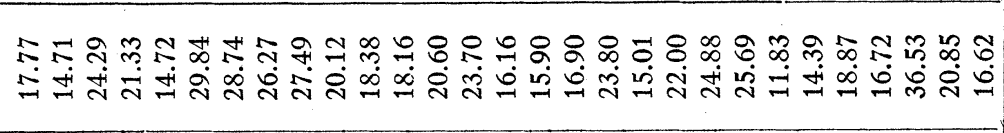 \\
\hline$\approx$ & 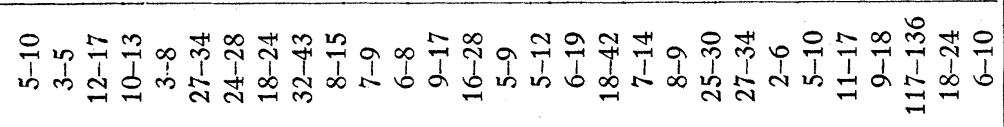 \\
\hline 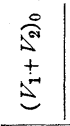 & 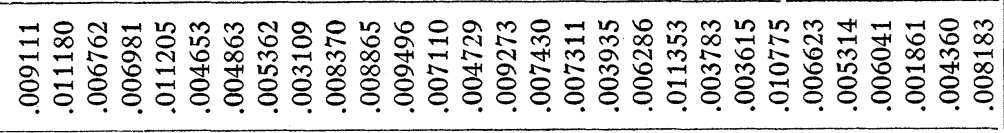 \\
\hline 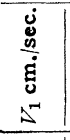 & 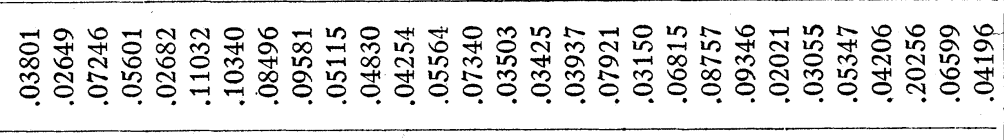 \\
\hline 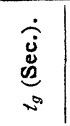 & 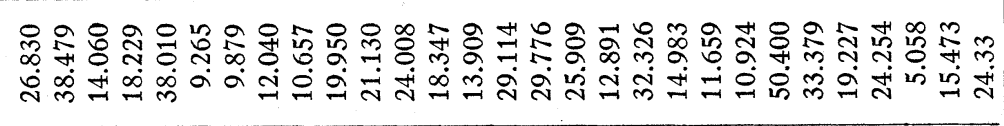 \\
\hline 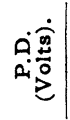 & 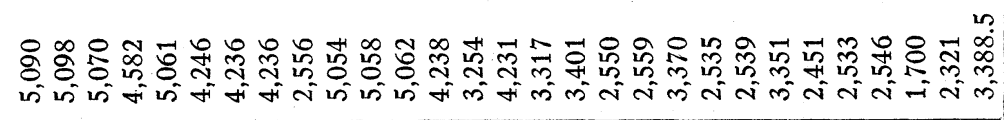 \\
\hline $\begin{array}{l}\dot{0} \\
0 \\
\dot{5} \\
\stackrel{5}{6}\end{array}$ & 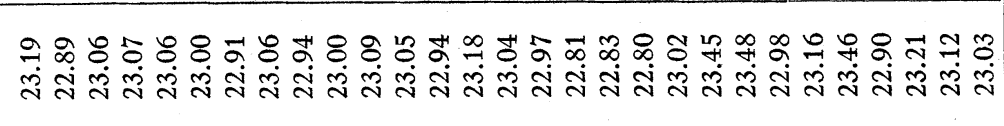 \\
\hline$\dot{\dot{z}}$ & 扁 \\
\hline
\end{tabular}


I 36

R. A. MILLIKAN.

[SEROND

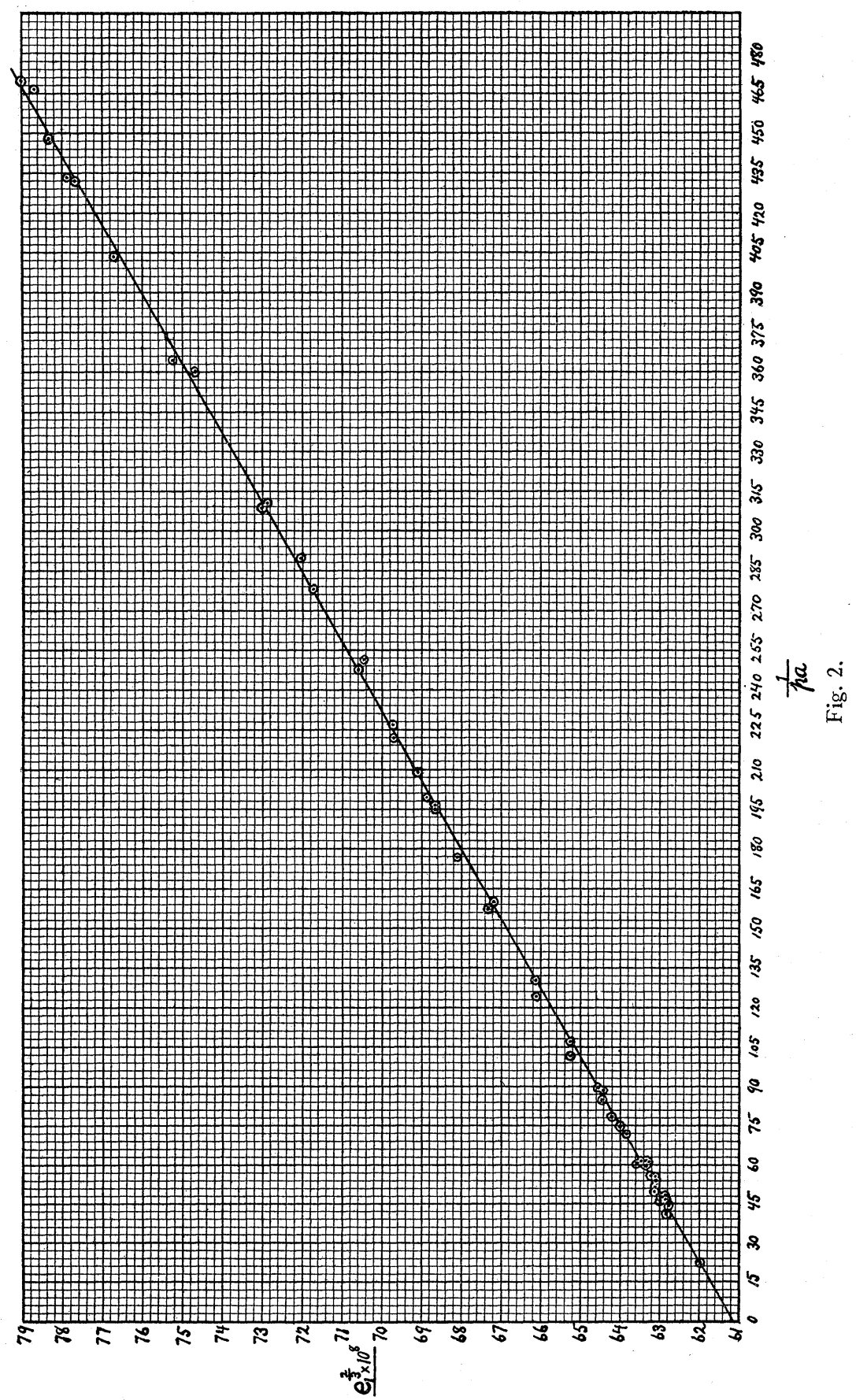




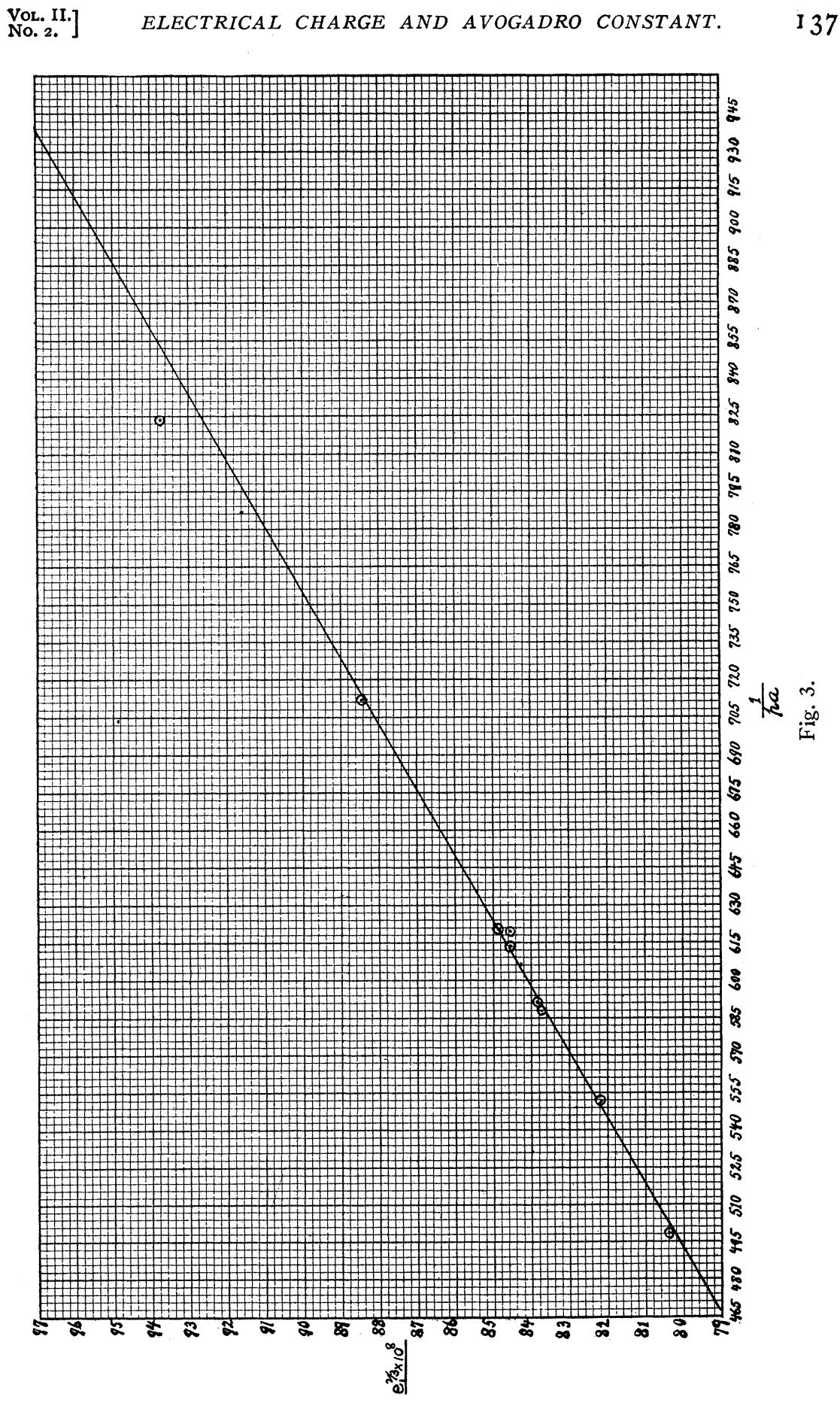


$y$ intercept (see equation 9). In view of the uncertainty in $l$ due to the fact that $k$ in the equation $\eta=k n m \bar{c} l$ has never been exactly evaluated, it was thought preferable to write the correction term to Stokes's law (see ( 2 and 3$)$ in the form $(1+b / p a)^{-1}$ instead of in the form $(1+A l / a)^{-1}$ and then to plot $e_{1}^{\frac{2}{3}}$ against $\mathrm{I} / p a$. Nevertheless in view of the greater ease of visualization of $l / a$ all the values of this quantity corresponding to successive values of $\mathrm{I} / p a$ are given in Table XX., $k$ being taken, merely for the purposes of this computation, as .3502 (Boltzmann). Fig. 2 shows the graph obtained by plotting the values of $e_{1}^{\frac{3}{3}}$ against $\mathrm{I} / p a$ for the first $5 \mathrm{I}$ drops of Table XX., and Fig. 3 shows the extension of this graph to twice as large values of $\mathrm{I} / p a$ and $e_{1}{ }^{\frac{2}{3}}$. It will be seen that there is not the slightest indication of a departure from a linear relation between $e_{1}^{\frac{2}{3}}$ and $\mathrm{I} / p a$ up to the value $\mathrm{I} / p a=620.2$ which corresponds to a value of $l / a$ of .4439 (see drop No. 58, Table XX.). Furthermore the scale used in the plotting is such that a point which is one division above or below the line in Fig. 2 represents in the mean an error of 2 in 7oo. It will be seen from Figs. 2 and 3 that there is but one drop in the 58 whose departure from the line amounts to as much as 0.5 per cent. It is to be remarked, too, that this is not a selected group of drops but represents all of the drops experimented upon during 60 consecutive days, during which time the apparatus was taken down several times and set up anew. It is certain then that an equation of the form (2) holds very accurately up to $l / a=.4$. The last drop in Fig. 3 seems to indicate the beginning of a departure from this linear relationship. Since such departure has no bearing upon the evaluation of $e$, discussion of it wil be postponed to another paper.

Attention may also be called to the completeness of the answers furnished by Figs. 2 and 3 to the questions raised in $\S 6$. Thus drops No. 27 and 28 have practically identical values of $\mathrm{I} / p a$ but while No. 28 carries, during part of the time, but I unit of charge (see Table XX.) drop No. 27 carries 29 times as much and it has about 7 times as large a diameter. Now if the small drop were denser than the large one (see assumption $3, \S 6$ ) or if the drag of the median upon the heavily charged drop were greater than its drag upon the one lightly charged (see assumtion $I, \S 6$ ), then for both these reasons drop 27 would move more slowly relatively to drop 28 then would otherwise be the case and hence $e_{1}^{\frac{3}{3}}$ for 27 would fall below $e_{1}^{\frac{2}{3}}$ for drop 28 . Instead of this the two $e_{1}^{3^{\prime}}$ s fall so nearly together that it is impossible to represent them on the present scale by two separate dots. Drops 52 and 56 furnish an even more striking confirmation of the same conclusion, for both drops have about the same value for $l / a$ and both are exactly on the line though No. 56 
carries at one time 68 times as heavy a charge as No. 52 and has three times as large a radius. In general the fact that Figs. 2 and 3 show no tendency whatever on the part of either the very small or the very large drops to fall above or below the line is experimental proof of the joint correctness of assumptions I, 3 , and $2 b$ of $\S 6$. The correctness of $2 a$ was shown by the agreement throughout Tables IV. to XIX. between $\mathrm{I} / n^{\prime}\left(\mathrm{I} / t_{F}{ }^{\prime}-\mathrm{I} / t_{F}\right)$ and $\mathrm{I} / n\left(\mathrm{I} / t_{g}+\mathrm{I} / t_{F}\right)$.

The values of $e^{3}$ and $b$ obtained graphically from the $y$-intercept and the slope in Fig. 2 are $e^{\frac{2}{3}}=61.13 \times 10^{-8}$ and $b=.0006254, p$ being measured, for the purposes of Fig. 2 and of this computation in mm. of $\mathrm{Hg}$ at $23^{\circ} \mathrm{C}$. and $a$ being measured in $\mathrm{cm}$. The value of $A$ (equations 2 and 3) corresponding to this value of $B$ is .874 instead of .817 as originally found. Cunningham's theory gives, in terms of the constants here used, $A=788 .^{1}$

Instead however of taking the result of this graphical evaluation of $e^{\frac{3}{3}}$ it is more accurate to reduce each of the observations on $e_{1}^{\frac{2}{3}}$ to $e^{\frac{2}{3}}$ by means of the above value of $B$ and the equation

$$
e^{\frac{z}{3}}\left(\mathrm{I}+\frac{b}{p a}\right)=e_{1}^{3} .
$$

The results of this reduction are contained in the last column of Table $\mathrm{XX}$. These results illustrate very clearly the sort of consistency obtained in these observations. The largest departure from the mean value found anywhere in the table amounts to 0.5 per cent., and "the probable error" of the final mean value computed in the usual way is 16 in 61,000 .

Instead however of using this final mean value as the most reliable evaluation of $e^{\frac{3}{3}}$ it was thought preferable to make a considerable number of observations at atmospheric pressure on drops small enough to make $t_{0}$ determinable with great accuracy and yet large enough so that the whole correction term to Stokes's law amounted to but a few per cent., since in this case, even, though there might be a considerable error in the correction-term constant $b$, such error would influence the final value of $e$ by an inappreciable amount. The first 23 drops of Table XX. represent such observations. It will be seen that they show slightly greater consistency than do the remaining drops in the table and that the correctionterm reductions for these drops all lie between $\mathrm{I} .3$ per cent. (drop No. I) and 5.6 per cent. (drop No. 23) so that even though $b$ were in error by as much as 3 per cent. (its error is actually not more than .5 per cent.) $e^{3}$ would be influenced by that fact to the extent of but o.I per cent. The mean value of $e^{\frac{2}{3}}$ obtained from the first 23 drops is $61.12 \times 10^{-8}$, a

1 Phys. ReV., 32, p. 380; also footnote. 
number which differs by I part in 3,400 from the mean obtained from all the drops.

When correction is made for the fact that the numbers in Table XX. were obtained on the basis of the assumption $\eta_{23}=.0001825$, instead of $\eta_{23}=.0001824$ (see $\S 2$ ) the final mean value of $e^{\frac{2}{3}}$ obtained from the first 23 drops is $61.085 \times 10^{-8}$. This corresponds to

$$
e=4.774 \times 10^{-10} \text { electrostatic units. }
$$

Since the value of the Faraday constant has now been fixed virtually by international agreement ${ }^{1}$ at 9,650 absolute electromagnetic units and since this is the number $N$ of molecules in a gram molecule times the elementary electrical charge, we have

$$
\begin{aligned}
N \times 4.774 \times 1 \mathrm{IO}^{-10} & =9,650 \times 2.9990 \times \mathrm{IO}^{10} ; \\
\therefore \quad N & =6.062 \times \mathrm{IO}^{23} .
\end{aligned}
$$

Although the probable error in this number computed by the method of least squares from Table XX. is but one part in 3,000 it would be erroneous to infer that $e$ and $N$ are now known with that degree of precision, for there are four constant factors entering into all of the results in Table $\mathrm{XX}$. and introducing uncertainties as follows. The coefficient of viscosity $\eta$ which appears in the $3 / 2$ power introduces into $e$ and $N$ a maximum possible uncertainty of o.I per cent. The distance between the condenser plates (I6.00 $\mathrm{mm}$.) is correct to .oI $\mathrm{mm}$., and therefore, since it appears in the Ist power in $e$, introduces a maximum possible error of something less than o.I per cent. The voltmeter readings have a maximum possible error of rather less than o.I per cent., and carry this in the Ist power into $e$ and $N$. The cross-hair distance which is uniformly duplicatable to one part in a thousand appears in the $3 / 2$ power and introduces an uncertainty of no more than o.I per cent. The other factors introduce errors which are negligible in comparison. The uncertainty in $e$ and $N$ is then that due to 4 continuous factors each of which introduces a maximum possible uncertainty of o.I per cent. Following the usual procedure we may estimate the uncertainty in $e$ and $N$ as the square root of the sum of the squares of these four uncertainties, that is, as 2 parts in $I, 000$. We have then finally:

and

$$
\mathrm{e}=4.774 \pm .009 \times 10^{-10}
$$

$$
\mathrm{N}=6.062 \pm .012 \times 10^{23} .
$$

The difference between these numbers and those originally found by the oil-drop method, viz., $e=4.89 \mathrm{I}$ and $N=5.992$ is due to the fact

${ }^{1}$ Atomic weight of silver I07.88. Electrochemical equivalent of silver o.orir8. 
that this much more elaborate and prolonged study has had the effect of changing every one of the three factors $\eta, A$, and $d$ ( $=$ cross-hair distance) in such a way as to lower $e$ and to raise $N$. The chief change however has been due to the elimination of the faults of the original optical system.

\section{i i. Comparison with Other Measurements.}

So far as I am aware, there is at present no determination of $e$ or $N$ by any other method which does not involve an uncertainty at least i 5 times as great as that represented in the above measurements.

Thus the radioactive method yields in the hands of Regener ${ }^{1}$ a count of the $\alpha$ particles which gives $e$ with an uncertainty which he estimates at 3 per cent. This is as high a precision I think as has yet been claimed for any $\alpha$ particle count, ${ }^{2}$ though Geiger and Rutherford's photographic registration ${ }^{3}$ method will doubtless be able to improve it.

The Brownian Movement method yields results which fluctuate between Perrin's value $e=4.24 \times$ IO $^{-10}$, and Fletcher's value, ${ }^{5} 5.0 \mathrm{I} \times$ IO $^{-10}$, with Svedberg's measurements ${ }^{6}$ yielding the intermediate number $4.7 \times 10^{-10}$.

The radiation method of Planck ${ }^{7}$ yields $N$ as a product of $\left(c_{2}\right)^{3}$ and $\sigma$. The latest Reichsanstalt value of $c_{2}$ is $1.436^{8}$ while Coblentz, ${ }^{9}$ as the result of extraordinarily careful and prolonged measurements obtains 1.4456. The difference in these two values of $\left(c_{2}\right)^{3}$ is 2 per cent. Westphal $^{10}$ estimates his error in the measurement of $\sigma$ at .5 per cent. though reliable observers differ in it by 5 per cent. or 6 per cent. We may take then 3 per cent. as the limit of accuracy thus far attained in measurements of $e$ or $N$ by other methods. The mean results by each one of the three other methods fall well within this limit of the value found above by the oil-drop method.

\section{i2. Computation of Other Fundamental Constants.}

For the sake of comparison and reference, the following fundamental constants are recomputed on the basis of the above measurements:

\footnotetext{
${ }^{1}$ Regener, Sitz. Ber. d. k. Preuss. Acad., 37, p. 948, 1909.

2 Rutherford and Geiger, Proc. Roy. Soc., 8I, p. I55, I908.

${ }^{3}$ Gciger and Rutherford, Phil. Mag., 24, p. 618, 1912.

${ }^{4}$ J. Perrin, C. R., I52, p. II65, I9II.

${ }^{5}$ H. Fletcher, Phys. Rev., 33, p. ro7, I9II.

${ }^{6}$ Svedberg, Arkiv f. Kemi, etc., utg. "af K. Sv. Vetensk. Akad., 2, 29, I906. See also Svedberg, "Die Existenz der Mölekule," p. r36. Leipzig, I9I 2.

7 Planck, Vorlesungen über die Theorie der Wärmestrahlung, 2d edition, I913, p. I66.

8 See Planck, Vorles., p. I63.

${ }^{9}$ Coblentz, Journal of the Washington Academy of Sciences, Vol. 3, p. 178, April, 1913.

${ }^{10} \mathrm{Wm}$. H. Westphal, Verh. d. D. Phys. Ges., 13, p. 987, Dec., I9r2.
} 
I. The number $n$ of molecules in I c.c. of an ideal gas at $0^{\circ} 76$ is given by

$$
n=\frac{N}{V}=\frac{6.062 \times \mathrm{IO}^{23}}{22,4 \mathrm{I} 2}=2.705 \times 10^{19} .
$$

2. The mean kinetic energy of agitation $E_{0}$ of a molecule at $0^{\circ} \mathrm{C}$. is given by

$$
\begin{gathered}
p V=\frac{1}{3} N m u^{2}=\frac{2}{3} N E_{0}=R T, \\
\therefore E_{0}=\frac{3}{2} \frac{p_{0} V_{0}}{N}=\frac{3 \times \mathrm{I}, 013,700 \times 22,412}{2 \times 6.062 \times 10^{23}}=5.62 \mathrm{I} \times \mathrm{IO}^{-14} \mathrm{ergs} .
\end{gathered}
$$

3. The constant $\epsilon$ of molecular energy defined by $E_{0}=\epsilon T$ is given by

$$
\epsilon=\frac{E_{0}}{T}=\frac{5.62 \mathrm{I} \times \mathrm{IO}^{-14}}{273 . \mathrm{II}}=2.058 \times \mathrm{IO}^{-16} \frac{\mathrm{ergs}}{\text { degrees }} .
$$

4. The Boltzmann entropy constant $k$ defined by $S=k \log W$ is given by

$$
k=\frac{R}{N}=\frac{p_{0} V_{0}}{T N}=\frac{2}{3} \epsilon=1.372 \times 10^{-16} \frac{\mathrm{ergs}}{\text { degrees }} .
$$

All of these constants are known with precisely the accuracy attained in the measurement of $e$.

5. The Planck "Wirkungsquantum" $h$ can probably be obtained considerably more accurately as follows than in any other way. From equation 292, p. I66, of the "Wärmestrahlung," we obtain ${ }^{2}$

$$
h=\frac{k^{\frac{4}{3}}}{c}\left(\frac{48 \pi \alpha}{a}\right)^{\frac{1}{3}}=\frac{\left(\mathrm{I} .372 \times 10^{-16}\right)^{\frac{4}{3}}}{2.999 \times 10^{10}} \cdot\left(\frac{48 \pi \mathrm{I} .0823}{7.39 \times 10^{-15}}\right)^{\frac{3}{3}}=6.620 \times 10^{-27}
$$

which gives $h$ with the same accuracy attainable in the measurement of $k^{\frac{4}{3}} / a$ in which $a$ is the Stefan-Boltzmann constant. If Westphal's estimate of his error in the measurement of this constant is correct, viz., 0.5 per cent., it would introduce an uncertainty of but 0.2 per cent. into $h$. This is about that introduced by the above determination of $k^{\frac{4}{3}}$, hence the above value of $h$ should not be in error by more than 0.4 per cent.

6. The constant $c_{2}$ of the Wien-Planck radiation law may also be computed with much precision from the above measurements. For also from equation 292 of the "Wärmestrahlung" we obtain

$$
c_{2}=\left(\frac{48 \pi \alpha k}{a}\right)^{\frac{3}{3}}=\left(\frac{48 \pi \mathrm{I} .0823 \mathrm{I} .372 \times 10^{-16}}{7.39 \times 10^{-15}}\right)^{\frac{1}{3}}=\mathrm{I} .4470 \mathrm{~cm} . \text { degrees. }
$$

${ }^{1}$ See Planck's Vorles., p. I29.

${ }^{2} c=$ velocity of light, $\alpha=$ a numerical factor, and $a=4 \sigma / c$. Westphal's value of $\sigma$ is $5.54 \times 10^{-5}$ which corresponds to $a=7.39 \times \mathrm{IO}^{-15}$. 
Since both $k$ and $a$ here appear in the $\mathrm{I} / 3$ power, the error in $c$ should be no more than 0.2 per cent., provided Westphal's error is no more than 0.5 per cent.

The difference between this and Coblentz's mean value, viz., $I .4456$ is but o.I per cent. The agreement is then entirely satisfactory. A further independent check is found in the fact that Day and Sosman's location of the melting point of platinum at $1755^{\circ} \mathrm{C} .{ }^{1}$ is equivalent to a value of $c_{2}=1.4475 .^{2}$ On the other hand, the last Reichsanstalt value of $c_{2}$, viz., I.437, is too low to fit well with these and Westphal's measurements. It fits perfectly however with a combination of the above value of $e$ and Shakespear's ${ }^{3}$ value of $\sigma$, viz., $\sigma=5.67 \times \mathrm{IO}^{-5}$.

\section{I3. Summary.}

The results of this work may be summarized in the following table in which the numbers in the error column represent in the case of the first six numbers estimated limits of uncertainty rather than the so-called "probable errors" which would be much smaller. The last two constants however involve Westphal's measurements and estimates and Planck's equations as well as my own observations.

\section{TABLE XXI.}

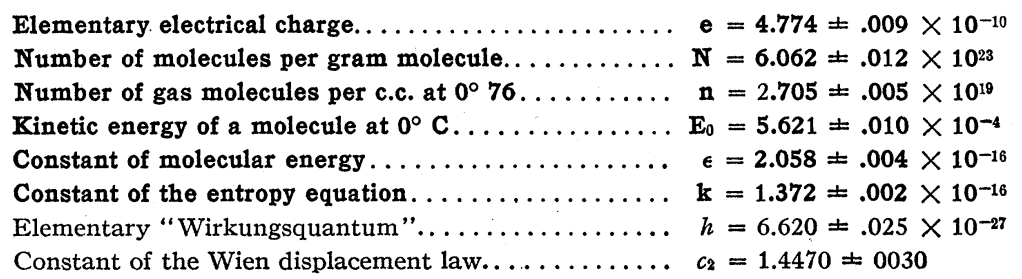

I take pleasure in acknowledging the able assistance of Mr. J. Yinbong Lee in making some of the above observations. Mr. Lee has also repeated with my apparatus the observations on oil at atmospheric pressure with results which are nearly as consistent as the above. Using my value of $b$ he obtains, as a mean of measurements on 14 drops, a value of $e$ which differs from the above by less than I part in 6,000, although its probable error computed as in the case of Table XX. is I part in 2,000 .

Ryerson Physical Laboratory, University OF Chicago, June 2, IgI3.

1 Amer. Jour. Sci., 30, p. 3, I9ro.

2 Coblentz, Journal of the Washington Academy of Sciences, Vol. 3, p. r3.

${ }^{3}$ G. A. Shakespear, Proc. Roy. Soc., 86, I80, I9II. 